\title{
Vacuole and Mitochondria Patch (vCLAMP) Protein Vam6 Is Involved in Maintenance of Mitochondrial and Vacuolar Functions under Oxidative Stress in Candida albicans
}

\author{
Xiaolong Mao, Li Yang, Yingzheng Liu, Congcong Ma, Tianyu Ma, Qilin Yu and Mingchun Li * \\ Key Laboratory of Molecular Microbiology and Technology, Ministry of Education, College of Life Science, \\ Nankai University, Tianjin 300071, China; fudan671@163.com (X.M.); 18783958821@163.com (L.Y.); \\ liuwenbo129@163.com (Y.L.); mcmacongcong@163.com (C.M.); matianyu3317658@163.com (T.M.); \\ yuqilin7007@163.com (Q.Y.) \\ * Correspondence: nklimingchun@163.com; Tel.: +86-22-23508506
}

check for updates

Citation: Mao, X.; Yang, L.; Liu, Y.; Ma, C.; Ma, T.; Yu, Q.; Li, M. Vacuole and Mitochondria Patch (vCLAMP) Protein Vam6 Is Involved in Maintenance of Mitochondrial and Vacuolar Functions under Oxidative Stress in Candida albicans. Antioxidants 2021, 10, 136. https://doi.org/ 10.3390/antiox10010136

Received: 14 December 2020

Accepted: 15 January 2021

Published: 19 January 2021

Publisher's Note: MDPI stays neutral with regard to jurisdictional claims in published maps and institutional affiliations.

Copyright: (C) 2021 by the authors. Licensee MDPI, Basel, Switzerland. This article is an open access article distributed under the terms and conditions of the Creative Commons Attribution (CC BY) license (https:// creativecommons.org/licenses/by/ $4.0 /)$.

\begin{abstract}
Candida albicans is one of the most common opportunistic fungal pathogens in human beings. When infecting host cells, C. albicans is often exposed to oxidative stress from the host immune defense system. Maintenance of mitochondrial and vacuolar functions is crucial for its resistance to oxidative stress. However, the role of vacuole and mitochondria patchs (vCLAMPs) in cellular oxidative stress resistance and in the maintenance of organelle functions remains to be elucidated. Herein, the function of the vCLAMP protein Vam6 in response to oxidative stress was explored. The results showed that the vam $6 \Delta / \Delta$ mutant exhibited obvious mitochondrial swelling, mtDNA damage, reduced activity of antioxidant enzymes, and abnormal vacuolar morphology under $\mathrm{H}_{2} \mathrm{O}_{2}$ treatment, indicating its important role in maintaining the structures and functions of both mitochondria and vacuoles under oxidative stress. Further studies showed that deletion of VAM6 attenuated hyphal development under oxidative stress. Moreover, loss of Vam6 obviously affected host tissue invasion and virulence of $C$. albicans. Taken together, this paper reveals the critical role of vCLAMPs in response to oxidative stress in C. albicans.
\end{abstract}

Keywords: Candida albicans; vCLAMPs; oxidative stress; Vam6

\section{Introduction}

C. albicans is a common opportunistic fungal pathogen in human beings [1]. Generally, C. albicans exists in a benign symbiotic state and does not show pathogenicity in healthy humans [2]. However, the mortality rate is reported to be $40 \%$ for patients with candidemia or invasive candidiasis [3]. C. albicans infections are thought to be caused by efficient escape from oxidative attacks of the immune system [4]. During invasion of host cells, the primary stress that C. albicans encounters is oxidative agents generated by host immune cells $[4,5]$. At the beginning of invasion, C. albicans first responds to external oxidative stress by rapid induction of gene expression involved in ROS scavenging [6]. However, when C. albicans successfully infects host tissues, its oxidative response system is instead in an inhibited state at the transcriptional level. After C. albicans is swallowed into macrophages, on the one hand, it can resist oxidative stress through morphological transformation [7], while on the other hand, it secretes extracellular antioxidant enzymes to resist oxidative stress. C. albicans can secrete a variety of antioxidant enzymes to the cell surface, the most important of which is superoxide dismutase (SOD). Several studies have suggested that vacuoles are quite important in promoting mycelial development and improving antioxidative stress [8-10]. Additionally, many studies have attempted to elucidate the nature of mitochondrial production of reactive oxygen species (ROS) and the target of subsequent oxidative damage [11]. Generally, there is a balance between ROS generation and elimination. Once imbalanced, it may lead to the accumulation of ROS in mitochondria, and virulence will decrease [12]. The above studies showed that the maintenance of 
mitochondrial morphology and function is essential for the survival of eukaryotic cells under oxidative stress [13]. However, the role of the vacuole and mitochondria patchs (vCLAMPs) in the oxidative response is not adequately understood.

In Saccharomyces cerevisiae, Vps39 is a membrane protein that belongs to the VPS (Vacuolar Protein Sorting) series. ScVps39 forms a complex with Ypt7, which is necessary for vacuolar protein transport and vesicle transport. In addition, ScVps39 plays an important role in the early vacuole fusion process and maintains the vacuole morphology. Recent research found that ScVps39 combines with Ypt7 and Tom40 to form mitochondrion and vacuole patches (vCLAMPs) [14-16]. Through vCLAMPs [15], the liposomes and ions between mitochondria and vacuole are exchanged [14,15]. However, the ScVps39 homologue Vam6 has never been studied in C. albicans.

In this study, we found that $C$. albicans possesses the homolog protein of the $S$. cerevisiae vCLAMP protein ScVps39 [17], named Vam6. A VAM6 deletion mutant was constructed by PCR-mediated two-step homologous recombination. Further investigations showed that Vam6 is required for maintaining vacuole morphology and function. Moreover, the vam6 $6 \Delta \Delta$ mutant exhibited obvious mitochondrial dysfunction, increased ROS levels, and reduced SOD1 activity under oxidative stress conditions. These results indicated that Vam6 was necessary in maintaining vacuolar and mitochondrial functions under the oxidative stress response. Further research revealed that deletion of VAM6 led to abnormal hyphal development under oxidative stress, and to attenuated host invasion and virulence. Taken together, these results revealed the role of vCLAMPs in oxidative stress response, thereby providing new avenues for treatment of $C$. albicans-associated infections.

\section{Materials and Methods}

\subsection{Strains and Plasmids Construction}

The strains used in this article are listed in Table S1. All C. albicans strains were generated in the BWP17 background. The primers are listed in Table S2. The vam6::ARG4 cassette was amplified by T100 Thermal Cycler (BIO-RAD Laboratories, Hercules, CA, USA) using the primer pair of the VAM6-5DR and VAM6-3DR from the plasmid pRS-Arg $\Delta$ SpeI. Secondly, we used pDDB57 plasmid as a template to amplify URA3 fragment, and obtained the vam6::URA3 gene box. The homozygous mutant (vam6::ARG4 /VAM6) was identified by PCR. The optimal amplification program was one cycle of $5 \mathrm{~min}$ at $94{ }^{\circ} \mathrm{C} ; 30$ cycles of 30s at $94{ }^{\circ} \mathrm{C}, 45 \mathrm{~s}$ at $52{ }^{\circ} \mathrm{C}$, and $3 \mathrm{~min}$ at $72{ }^{\circ} \mathrm{C}$; one cycle of $10 \mathrm{~min}$ at $72{ }^{\circ} \mathrm{C}$. A wild-type band of $3.5 \mathrm{~kb}$ and an ARG4 band of $2.4 \mathrm{~kb}$ are shown in the Figure S1A. The homozygous mutant strains (vam6::ARG4/vam6:: URA3) were identified by PCR. Only the ARG4 band of $2.4 \mathrm{~kb}$ and URA3 band of $2.1 \mathrm{~kb}$ were found (Figure S1B). Finally, vam $6 \Delta / \Delta$ was selected on SC medium $(0.67 \%$ yeast nitrogen base without amino acids, $2 \%$ glucose, $0.2 \%$ complete amino acid mixture, adding $80 \mu \mathrm{g} / \mathrm{mL}$ uridine) [18]. To obtain vam6 $\Delta / \Delta+V A M 6$ (Figure S1E), the pDDB78-VAM6 plasmid was transformed into vam6 $\Delta / \Delta$ after Nru I digested. At the same time, the location of plasmid pAu34M-VAM6-GFP was linearized by $B g l$ II restriction endonuclease, and transformed into WT to obtain WT-VAM6-GFP strain.

To assay the virulence of $C$. albicans, a $4.9 \mathrm{~kb} B g l$ II-Pst I fragment from pLUBP (encoding URA3 and its adjacent gene, IRO1) was introduced into the WT, vam $6 \Delta / \Delta$, and vam $6 \Delta / \triangle+V A M 6$ mutant, obtaining the strains $\mathrm{WT}^{\mathrm{a}}$, vam $6 \Delta / \Delta^{\mathrm{a}}$ and vam $6 \Delta / \triangle+V A M 6^{\mathrm{a}}$ with $U R A 3$ reintroduced to their common locus.

\subsection{Fluorescence Microscopy}

Fluorescence microscopy was used to observe the location of Vam6-GFP in C. albicans. WT-VAM6-GFP cells were cultured in a liquid medium, adjusted to an $\mathrm{OD}_{600}$ of 0.1 in SC medium, cultured for $4 \mathrm{~h}$, and then harvested. After MitoTracker Red (dissolved in dimethyl sulfoxide (DMSO), final concentration: $1 \mathrm{mmol} / \mathrm{mL}$ ) staining, the cells were observed by fluorescence microscope [19]. The vacuoles were observed after FM4-64 (N-(3-triethylammoniumpropyl)-4-(6-(4-(diethylamino) phenyl) hexatrienyl) pyridinium 
dibromide) (dissolved in dimethyl sulfoxide (DMSO), final concentration: $50 \mu \mathrm{g} / \mathrm{mL}$; Sigma, St. Louis, MO, USA) staining [20] in the same way.

\subsection{Flow Cytometry}

To measure the mitochondrial membrane potential (MMP), cells were cultured in YPD medium (containing $5 \mathrm{~mm} / \mathrm{L} \mathrm{H}_{2} \mathrm{O}_{2}$ ) for $1 \mathrm{~h}$. Then cells were incubated with a cationic lipid fluorescent dye (JC-1, dissolved in DMSO, final concentration: $1 \mu \mathrm{g} / \mathrm{mL}$; Sigma-Aldrich, St. Louis, MO, USA) at $30^{\circ} \mathrm{C}$ for $30 \mathrm{~min}$, and the cells were measured by flow cytometry (FACS Calibar flow cytometry, BD, San Jose, CA, USA).

\subsection{Electron Microscopic Observation}

Transmission electron microscopy was used to view the vacuole and mitochondria patch (vCLAMP). The strains were cultured in YPD (containing $5 \mathrm{mM} \mathrm{H}_{2} \mathrm{O}_{2}$ ) for $1 \mathrm{~h}$, and then harvested, washed twice by PBS. The cells were suspended in $2.5 \%$ glutaraldehyde fixative and fixed at $4{ }^{\circ} \mathrm{C}$ for $12 \mathrm{~h}$. Then cells were washed three times by PBS. The cells were then collected by centrifugation, $1 \%$ osmic acid was added, and the cells were suspended and fixed at room temperature for $1 \mathrm{~h}$. The cells were collected by centrifugation and washed three times by PBS for 10 min each time. Cells were fixed by gradient ethanol dehydration. The cells were collected by centrifugation and embedded. The embedded samples were cut into 50-100 $\mathrm{nm}$ tissue sections using an ultramicrotome. The cuts were then transferred onto a copper mesh and dried. The samples were observed by a transmission electron microscope (Tecnai G2 F-20, FEI Company, Hillsboro, OR, USA).

Immunolabeling was performed using anti-GFP antibody (MBL598, 1:100) for $2 \mathrm{~h}$ at room temperature followed by Goat Anti-Rabbit IgG/Gold $(10 \mathrm{~nm}$ ) (Solarbio, 1:100 dilution) for $30 \mathrm{~min}$ at room temperature. The samples were further stained with uranium acetate and citric acid, dried, and observed by a transmission electron microscope (FEI Company, Hillsboro, OR, USA).

\subsection{Determination of Intracellular ATP, Reactive Oxygen Species (ROS) and SOD1 Levels}

Intracellular ATP concentration was measured using the ATP-based creatine kinase catalyzing adenosine triphosphate and creatine to produce creatine phosphate, as previously described [21,22].

Intracellular ROS concentration was measured using $2^{\prime}, 7^{\prime}$-Dichlorodihydrofluorescein diacetate (DCFH-DA) (Shanghai, China), which is oxidized by intracellular ROS to form fluorescence DCF, as previously described [1,4]. The cells of the experimental group and the treatment group were collected, and the cells were stained with DCFH-DA (final concentration: $10 \mu \mathrm{mol} / \mathrm{mL}$ ) and washed by PBS. The fluorescence intensity of the cells was measured by a fluorescent multilabel reader 2300 (Enspire $^{\mathrm{TM}}$, Perkin Elmer, Ltd., Singapore).

The activity of SOD1 in the cells was detected using a superoxide dismutase (SOD1) assay kit (Hydroxylamine method) (Nanjing Jiancheng Bio., Nanjing, China). This assay was based on the superoxide anion radical generated by the xanthine and xanthine oxidase reaction system. The latter can oxidize hydroxylamine to form nitrite and appear purple under the action of a color developer [21]. The optical density at $550 \mathrm{~nm}$ of the samples was detected by a spectrophotometer (BIO-RAD Laboratories, Hercules, CA, USA).

\subsection{Hyphal Induction}

To explore the role of Vam6 in hyphal development of $C$. albicans, Spider and RPMI1640 medium (RP MI-1 640 po wd er $1.04 \%$, MO PS $0.418 \%$, pH 7.0) were selected as solid hypha-inducing media. Strains were cultured at $30^{\circ} \mathrm{C}$ and $37^{\circ} \mathrm{C}$ for six days to observe hyphal development. To further confirm the role of Vam6 in hyphal development, the strains were also cultured in liquid hypha-inducing medium, i.e., the liquid RPMI-1640 medium, and then stained by Calcofluor White (CFW; final concentration: $10 \mathrm{mg} / \mathrm{mL}$ ) for fluorescent microscopy. 


\subsection{Assay of Macrophage-Killing Capacity}

To evaluate the interaction between the murine macrophages and C. albicans, the macrophage RAW246.7 cells (obtained from the Cell Resource Center, China Academy of Medical Science, Beijing, China) were suspended in DMEM medium containing 10\% fetal bovine serum (FBS), and cultured at $37{ }^{\circ} \mathrm{C}$ with $5 \% \mathrm{CO}_{2}$ concentration for $24 \mathrm{~h}$, so that the cell concentration was about $5 \times 10^{5}$ cells $/ \mathrm{mL}$. The log phase of C. albicans was suspended in RPMI-1640 medium at a concentration of $1 \times 10^{6}$ cells. After the cell suspension was incubated with macrophages for a certain period, the mortality of $C$. albicans was determined by CFU counting method. The percentage of macrophages damaged by C. albicans was determined by the propidium iodide (PI) staining method.

\subsection{Virulence Assay}

All mice used in this study were placed at a constant temperature of $24 \pm 2{ }^{\circ} \mathrm{C}$ in room, a $12 \mathrm{~h}$ light/dark cycle, lighted at 7:00 in the morning, and food and drink at conditions of freedom in Nankai University Medical College. Every effort was made to minimize animal suffering and animal populations.

Ten 4-6-week-old ICR female SPF mice were used per group, obtained from the HKF Bioscience CO., LTD., Beijing, China. The $\mathrm{WT}^{\mathrm{a}}$, vam $6 \Delta / \Delta^{\mathrm{a}}$ and vam $6 \Delta / \Delta+V A M 6^{\mathrm{a}}$ strains were cultured in YPD medium to $12 \mathrm{~h}$, washed with PBS, and mice were injected through the tail vein (the injection cells were $5 \times 10^{5}$ ). The death of the mice was recorded after the first day of vaccination. The survival rate of the mice and statistical analysis were performed by the SPSS software (Version 20, IBM, Chicago, IL, USA). On the third day after fungal infection, three mice in each group were sacrificed, and the kidneys were sampled, weighed and homogenized with PBS buffer. The suspensions of kidney homogenates were diluted and plated on the YPD solid media. After two days of incubation at $30^{\circ} \mathrm{C}$, fungal colonies were counted and the results were normalized by kidney weight. At the same time, some kidneys were taken and fixed with $10 \%$ formalin for $24 \mathrm{~h}$. After hematoxylin-eosin staining, the kidney sections were observed by a light microscope (BX53, Olympus, Tokyo, Japan) to evaluate the degree of inflammation and tissue damage by the fungal cells.

\section{Results}

\subsection{Vam6 Is Critical for Formation of vCLAMPs}

Most proteins of vCLAMPs are located at the mitochondrion-vacuole connecting sites. In this study, Vam6 (orf 19.1567) was found in C. albicans through the online NCBI BLASTP software (https://www.ncbi.nlm.nih.gov/Structure/cdd/docs/cdd_search.html), a homologous protein of $S$. cerevisiae Vps39. To determine whether Vam6 is a vCLAMP protein, the cellular location of Vam6 in C. albicans was investigated by fluorescent labeling. Fluorescence microscope observation showed that Vam6-GFP was located both on the vacuolar membrane labeled with FM4-64, and on the mitochondria labeled by MitoTracker Red (Figure 1A). Through immunoelectron microscopy (IEM), Vam6 itself accumulated in vCLAMP (Figure 1B). The results indicated that Vam6 may be a protein localized at vCLAMPs.

To study the role of Vam6 in the formation of vCLAMPs, mitochondria were labeled by Csp37-GFP, a fusion protein localized on the outer membrane of mitochondria in C. albicans (Figure S2), could be used as a mitochondria marker [22], and vacuoles were labeled by FM4-64 in wild-type (WT) and vam6 $\Delta / \Delta$ strains. Fluorescence microscopy showed that the WT strain had abundant mitochondrion-vacuole colocalizing sites (indicated by white arrows, Figure 1C, up), indicating normal formation of vCLAMPs in the WT cells. In contrast, vam $6 \Delta / \Delta$ showed no obvious mitochondrion-vacuole colocalizing sites (Figure 1C, bottom), suggesting a severe defect in formation of vCLAMPs in the mutant. Transmission electron microscopy (TEM) observation further confirmed that the WT and reconstituted strains had regular mitochondria adhering to the vacuoles, while the mutant showed fragmented mitochondria not contacting the vacuoles (Figure 1D). These results 
revealed that Vam6, as a vCLAMP-localizing protein, is required for normal formation of vCLAMPs in C. albicans.

A

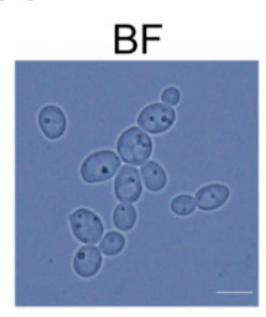

BF

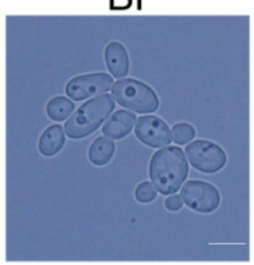

Mitochondria
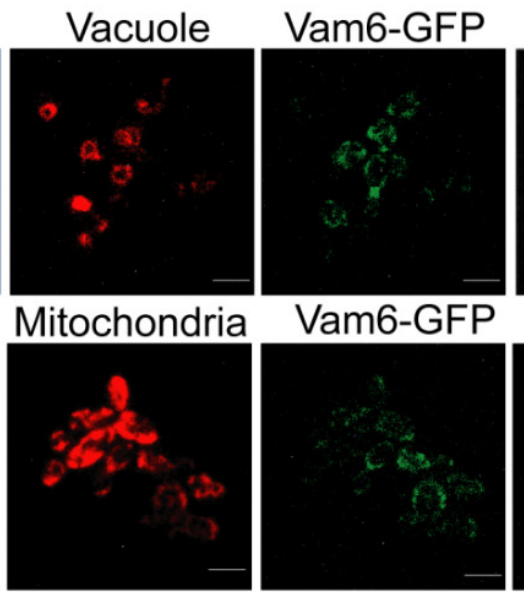

Vam6-GFP

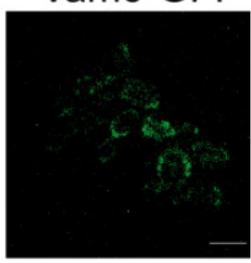

C
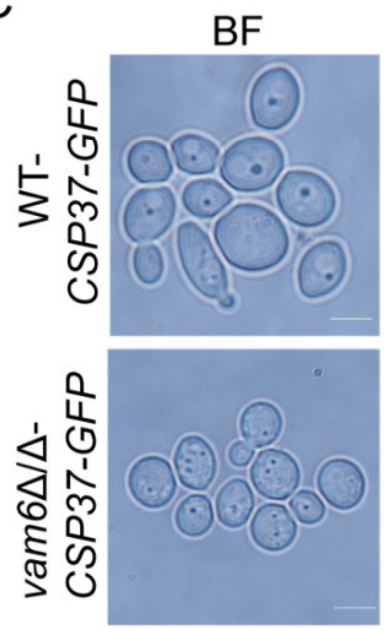

$\mathrm{D}$
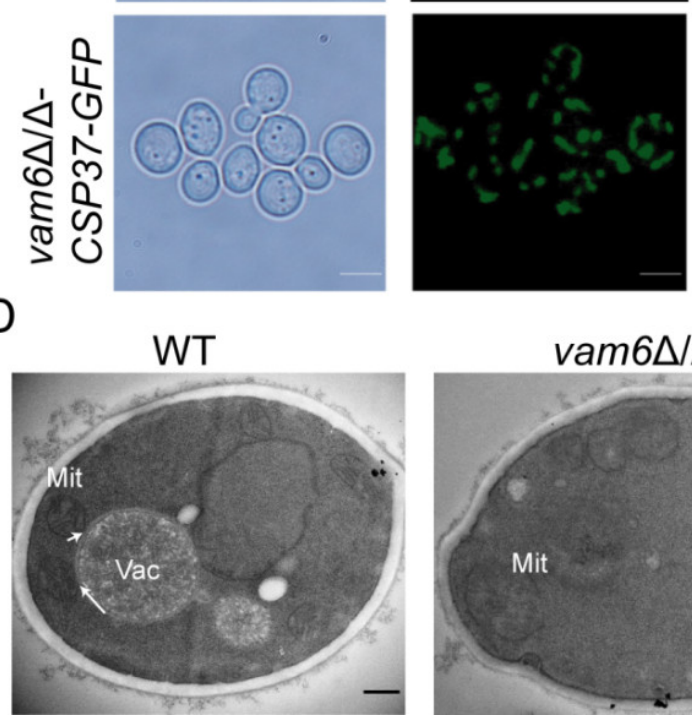

$\operatorname{vam} 6 \Delta / \Delta$
B

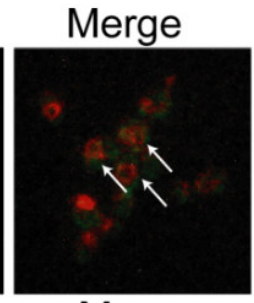

Merge
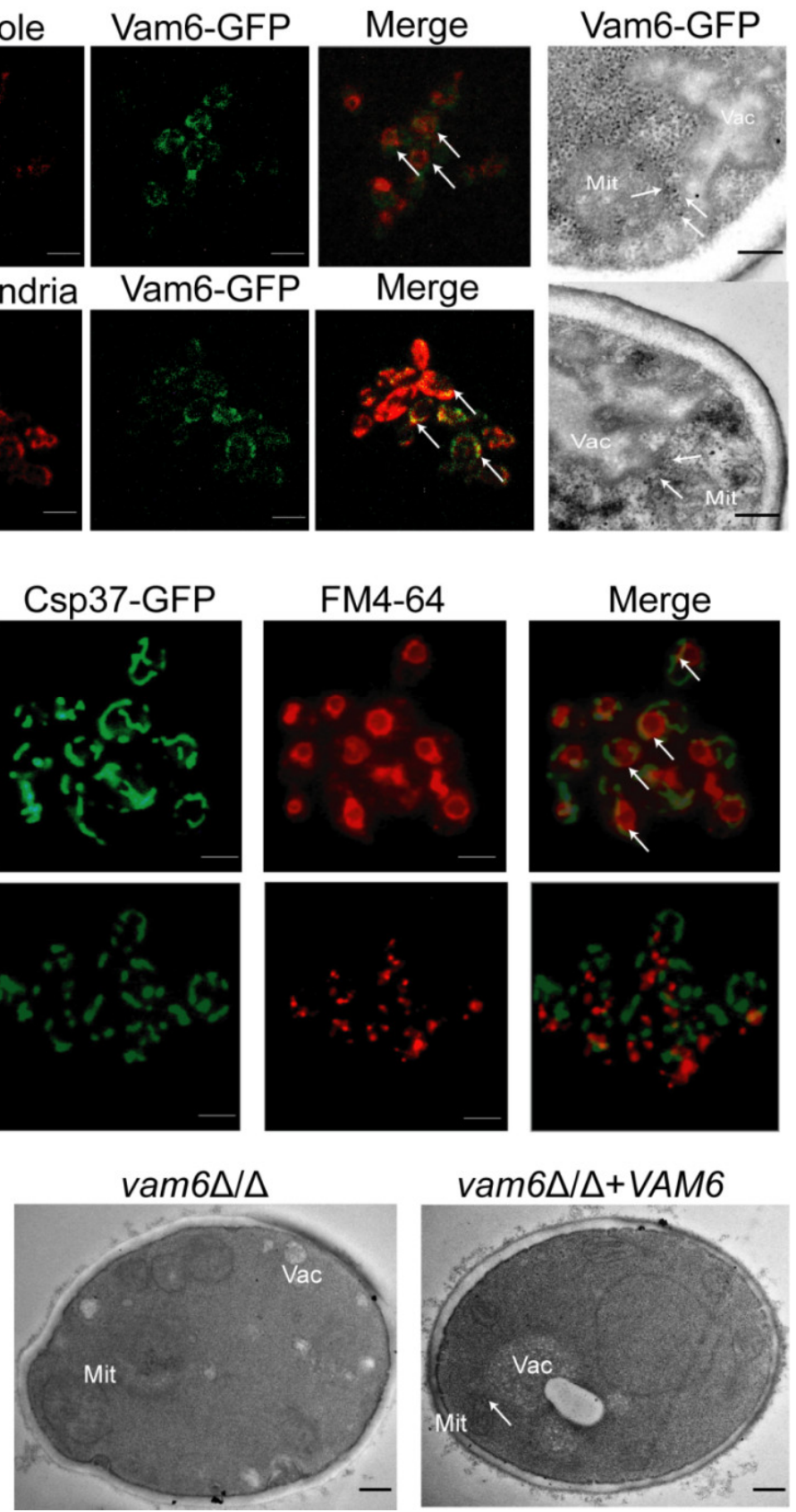

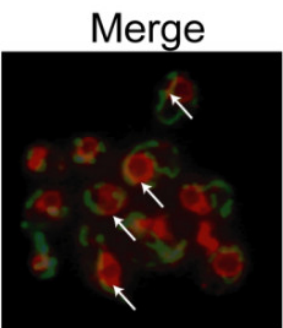

FM4-64
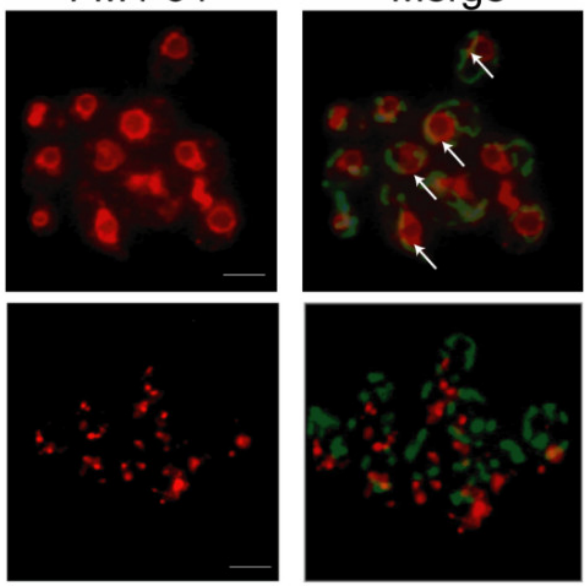

vam $6 \Delta / \triangle+V A M 6$

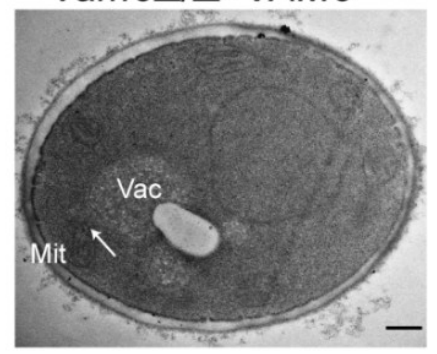

Figure 1. Intracellular localization of Vam6 and its role in formation of vCLAMPs. (A) Localization of Vam6 in C. albicans. Bar $=5 \mu \mathrm{m}$. (B) The localization of Vam6-GFP was observed by immuno transmission electron microscope. The Vam6-GFP was visualized using Anti-GFP IgG/Rabbit and Goat Anti-Rabbit IgG/Gold (10 nm). Mit, mitochondria; Vac, vauoles. Bar $=200 \mathrm{~nm}$. (C) Colocalization of the mitochondria and the vacuoles in WT and vam $6 \Delta / \Delta$. The white arrows indicate vCLAMPs. Bar $=5 \mu \mathrm{m}$. (D) TEM images of the cells under oxidative stress. The cells were cultured in liquid YPD containing $5 \mathrm{mM} \mathrm{H}_{2} \mathrm{O}_{2}$ for $1 \mathrm{~h}$, fixed and cut for TEM observation. Bar $=200 \mathrm{~nm}$. 


\subsection{Deletion of VAM6 Leads to Hypersensitivity to Oxidative Stress}

Yvc1, one of the calcium signaling members, plays a critical role in cell tolerance to oxidative stress. The $y v c 1 \Delta / \Delta$ strain is always used as an oxidative stress sensitive strain [1]. In the process of infecting the host, oxidative stress is an inevitable challenge for C. albicans. To further investigate the role of Vam6 in C. albicans cellular processes, sensitivity of the vam6 $\Delta / \Delta$ mutant to oxidative stress was evaluated in $\mathrm{H}_{2} \mathrm{O}_{2}$-containing plates. When cultured in YPD contained $5 \mathrm{mM}$ or $7 \mathrm{mM} \mathrm{H}_{2} \mathrm{O}_{2}$, growth of vam6 $\Delta / \Delta$ was significantly inhibited as compared to the WT strain (Figure 2A). Similar growth inhibition was observed in the $y v c 1 \Delta / \Delta$ strain, an oxidative stress-sensitive strain [1]. Furthermore, in order to detect whether cell death was caused by exogenous oxidative stress, the dead cells were stained by propidium iodide (PI). Consistently, the mutant had much higher death rate than the WT and reconstituted strains under oxidative stress $(>20 \%$ versus $<10 \%$ ) (Figure 2B). Moreover, ROS assays with 2', $7^{\prime}$-dichlorodihydrofluorescein diacetate (DCFH-DA) staining revealed that the mutant exhibited higher intracellular ROS levels than the control strains (Figure 2C).

A
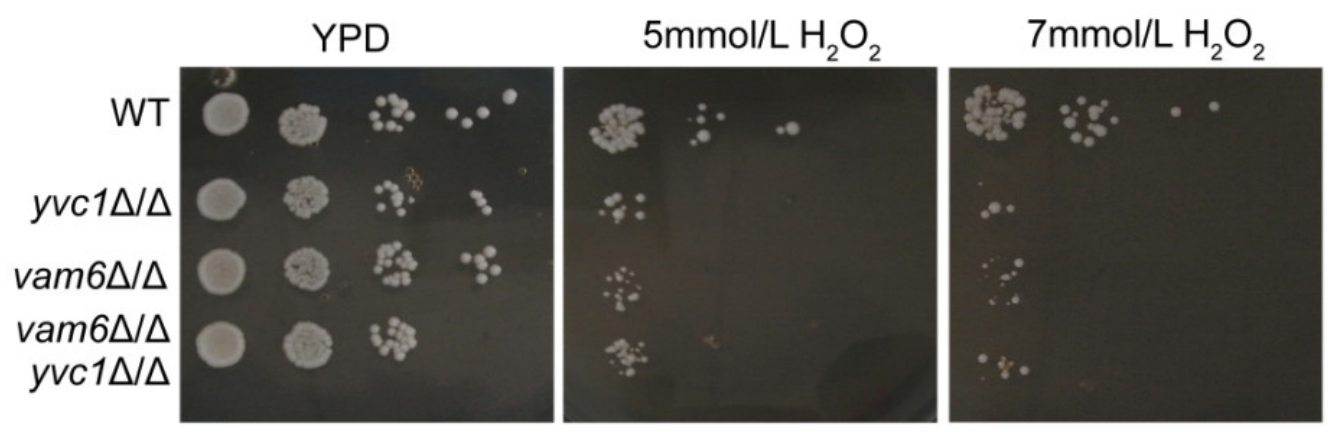

\section{$50 \mathrm{mmol} / \mathrm{L} \mathrm{Cu}^{2+}$}

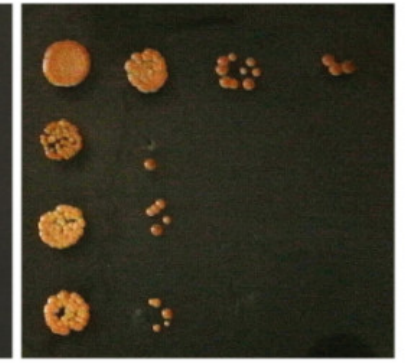

B

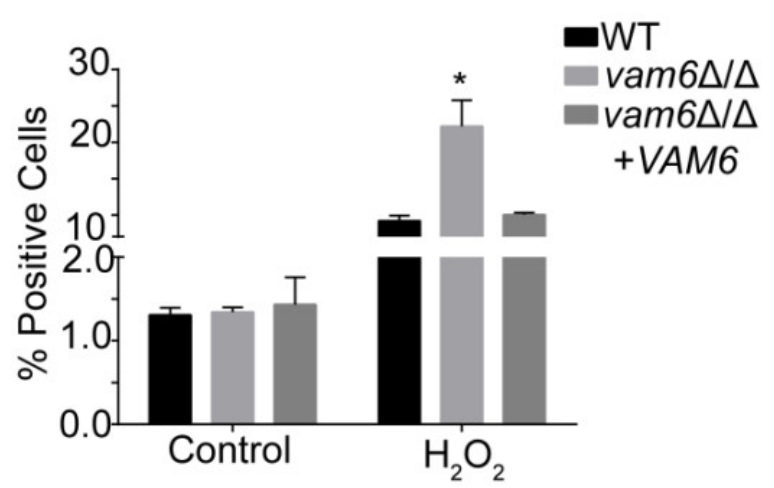

C

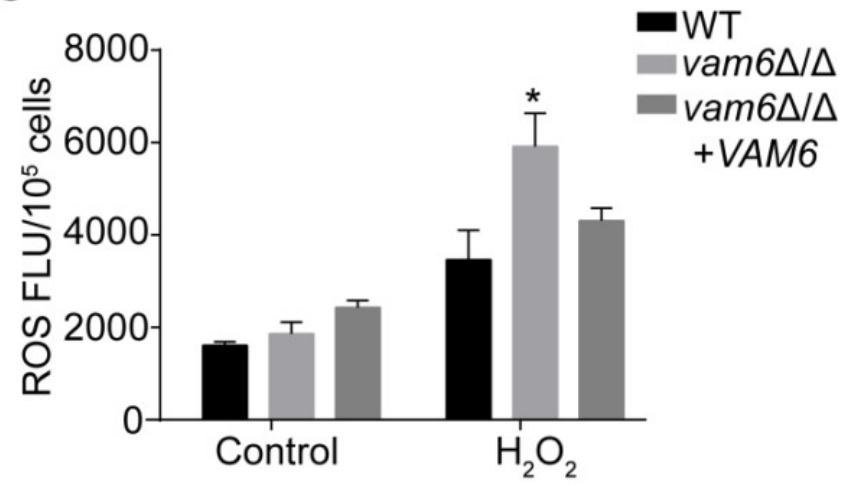

Figure 2. Hypersensitivity of the vam $6 \Delta / \Delta$ mutant to oxidative stress. (A) Cells were overnight cultured in liquid YPD,

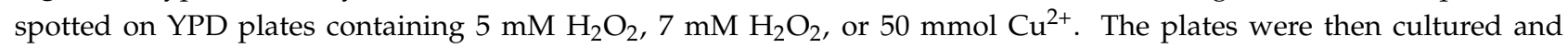
photographed. (B) Percent of dead cells under treatment of $5 \mathrm{mM} \mathrm{H}_{2} \mathrm{O}_{2}$ for $1 \mathrm{~h}$. The treated cells were stained by PI and observed by fluorescence microscopy for calculation of PI-positive cells. (C) Intracellular ROS levels of the strains revealed by DCFH-DA staining. * indicates significant difference between the mutant and the control strains $(p<0.05)$.

Ion homeostasis is closely involved in intracellular redox homeostasis, and disturbance in ion homeostasis may result in oxidative stress [4]. Plate growth assays further showed that the vam6 $\Delta / \Delta$ mutant, similar to $y v c 1 \Delta / \Delta$, exhibited hypersensitivity to $50 \mathrm{mmol} / \mathrm{L}$ of $\mathrm{Cu}^{2+}$ (Figure 2A). However, as compared to WT and $y v c 1 \Delta / \Delta$, vam6 $\Delta / \Delta$ was not sensitive to $\mathrm{Ca}^{2+}, \mathrm{Mn}^{2+}, \mathrm{Mg}^{2+}$ and $\mathrm{Zn}^{2+}$ (Figure S3). Taken together, loss of Vam6 rendered the cells hypersensitive to oxidative stress, indicating a critical role of Vam6 in oxidative stress resistance in this pathogen. 


\subsection{Deletion of VAM6 Affects Vacuolar Morphology and Function under Oxidative Stress}

It was reported that deletion of $\mathrm{ScVps} 39$ not only results in abnormal morphology and function of vacuoles, but also disrupts the integrity of the vacuole structure in S. cerevisiae [23]. We therefore investigated the role of Vam6 in maintaining the vacuolar structure in C. albicans. FM4-64 staining showed that the morphology of vacuoles in vam $6 \Delta / \Delta$ strain was abnormal, and the vacuoles could not aggregate to form large vacuoles (Figure 3A). Especially, under treatment of $\mathrm{H}_{2} \mathrm{O}_{2}$, while the control strains maintained normal round-like vacuoles, the mutant exhibited whole-cell distribution of the vacuoles with no regular morphology (Figure 3A). These observations showed that Vam6 is involved in vacuolar fusion and maintenance of vacuolar structure.

A

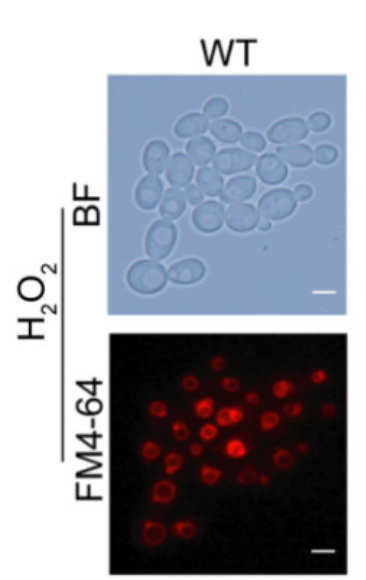

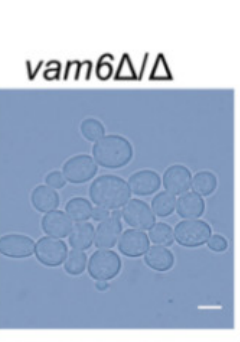

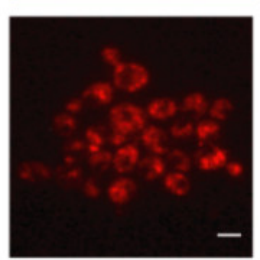

vam $6 \Delta / \Delta$ +VAM6
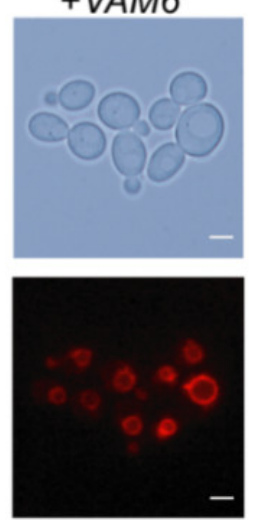

B

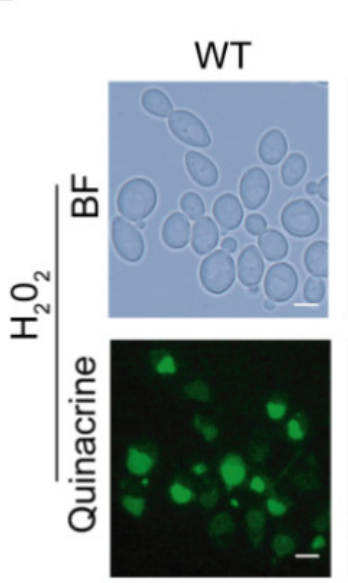

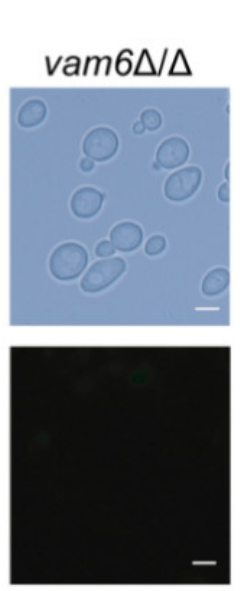

vam $6 \Delta / \Delta$ +VAM6
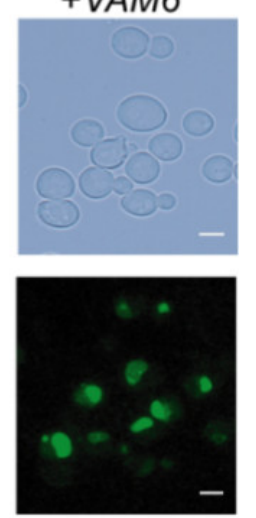

Figure 3. Deletion of VAM6 has an impact on vacuolar morphology and function. (A) Vacuolar morphology of the strains revealed by FM4-64 staining. Vacuolar morphology was observed by a fluorescence microscopy after FM4-64 staining. Bar $=5 \mu \mathrm{m}$. (B) Vacuolar $\mathrm{pH}$ under oxidative stress revealed by Quinacrine staining. Bar $=5 \mu \mathrm{m}$.

Acidic $\mathrm{pH}$ in vacuoles is required for normal vacuolar functions, e.g., degradation of proteins and damaged organelles that are transported into the vacuoles [24,25]. Vacuolar $\mathrm{pH}$ assays by Quinacrine staining revealed that both the WT and reconstituted strains had normal vacuolar acidic $\mathrm{pH}$, leading to strong fluorescence emission in the vacuoles (Figure 3B). In contrast, vam $6 \Delta / \Delta$ did not exhibit fluorescence emission, indicating that the mutant failed to maintain acidic $\mathrm{pH}$ in the vacuoles. Together, these results suggested that Vam6 is required for maintaining vacuolar structures and functions in C. albicans.

\subsection{Vam6 Is Required for Maintaining Mitochondrial Morphology under Oxidative Stress}

To investigate the role of Vam6 in mitochondrial functions, the mitochondria were visualized by MitoTracker Red staining [26]. Generally, the mitochondria had a tubular structure, exhibiting a bifurcated, cross-linked network in WT under oxidative stress. Moreover, the vam6 $\Delta / \Delta+V A M 6$ significantly restore normal mitochondrial network (Figure 4). In contrast, the mitochondria in vam6 $\Delta / \Delta$ were significantly fragmented under oxidative stress (Figure 4). Therefore, these results revealed that Vam6 plays an important role in maintaining normal mitochondrial morphology under oxidative stress. 


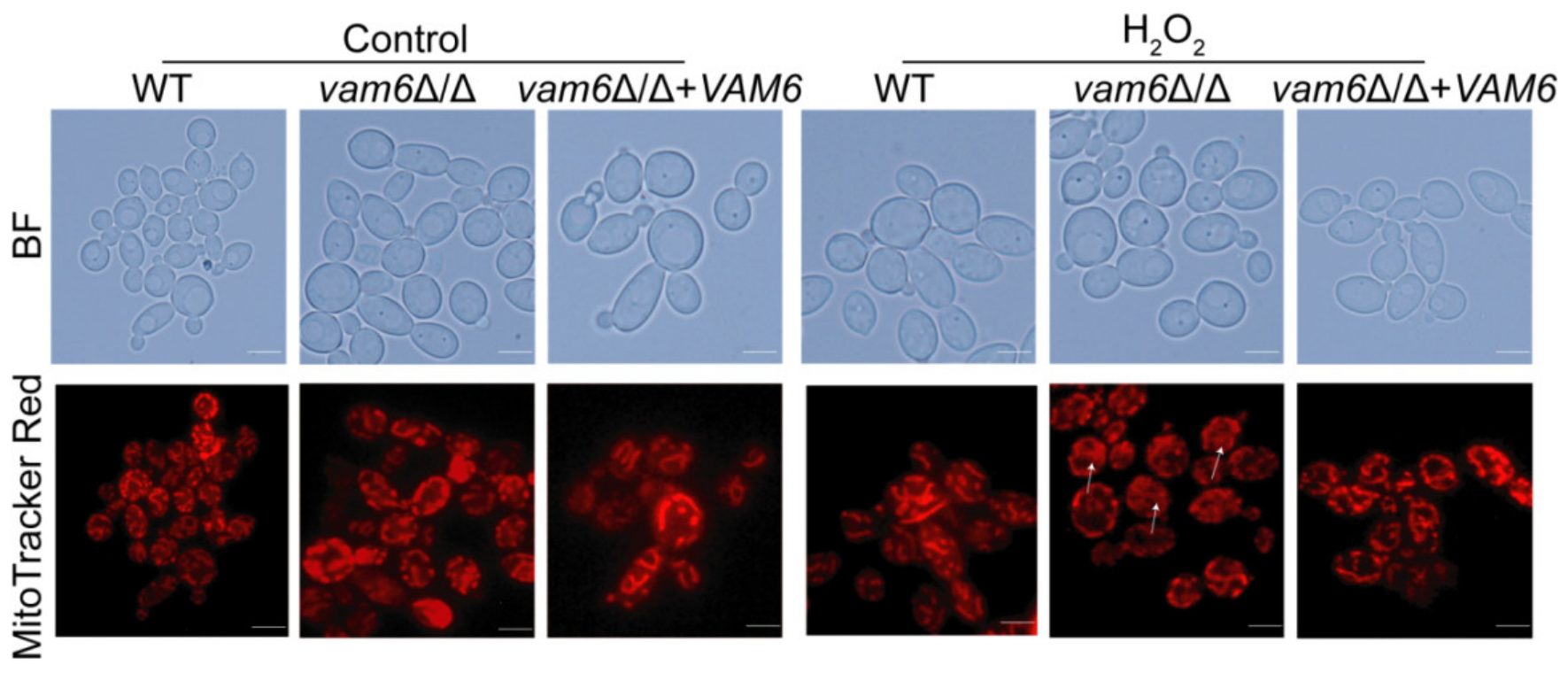

Figure 4. Deletion of VAM6 impairs mitochondrial morphology under Mitochondrial morphology was abnormal under oxidative stress. Fluorescence microscopy images of the strains stained by MitoTracker Red. The cells were cultured in liquid YPD containing $5 \mathrm{mM} \mathrm{H}_{2} \mathrm{O}_{2}$ or not, stained, and observed. Bar $=5 \mu \mathrm{m}$.

\subsection{Deletion of VAM6 Leads to Mitochondrial Dysfunction}

In S. cerevisiae, mitochondrial DNA (mtDNA, e.g., COX2, ATP6) stability affects cell growth. In this study, the role of Vam6 in maintaining mtDNA stability was explored by real-time quantitative PCR (qRT-PCR). The result showed that the copy numbers of tested mtDNA genes were significantly reduced in vam $6 \Delta / \Delta$ as compared to control strains under $\mathrm{H}_{2} \mathrm{O}_{2}$ conditions (Figure $5 \mathrm{~A}$ ) confirming that Vam6 was involved in maintaining mtDNA stability under oxidative stress.

Mitochondrial activity is closely related to mitochondrial ability to produce ATP [27,28]. Therefore, the effect of VAM6 deletion on mitochondrial ATP production was detected by the ATP assay kit. As compared to the WT and reconstituted strains, the mutant had lower ATP levels under oxidative stress (Figure 5B), indicating an impairment of mitochondrial function in the mutant. Moreover, MTT assays showed that the activity of $\mathrm{NAD}(\mathrm{P}) \mathrm{H}$-dependent enzymes, one of the markers reflecting mitochondrial function [10], was significantly reduced in vam $6 \Delta / \Delta$ as compared to control strains under $\mathrm{H}_{2} \mathrm{O}_{2}$ conditions (Figure 5C).

Studies have shown that mitochondria dysfunction was closely associated with a decrease in mitochondrial membrane potential (MMP) [29]. In this study, the cationic lipid fluorescent dye JC-1 was used to study the effect of VAM6 deletion on MMP by flow cytometry. The results showed that only $4.55 \%$ of the mutant cells showed decreased MMP, which was slightly higher than the control strains under the normal condition (Figure 5D). However, under the oxidative stress, the mutant showed higher levels of cells with decreased MMP than the control strains (15.26\% versus $5.23 \%$ or $5.73 \%$ ). Taken together, these data indicate that Vam6 plays a critical role in the maintenance of mitochondrial function under oxidative stress. 
A

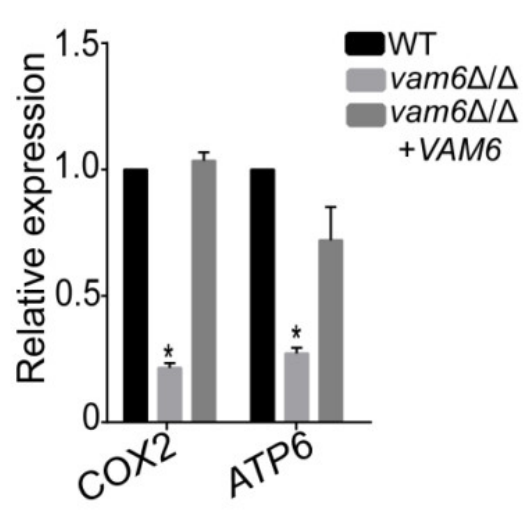

D
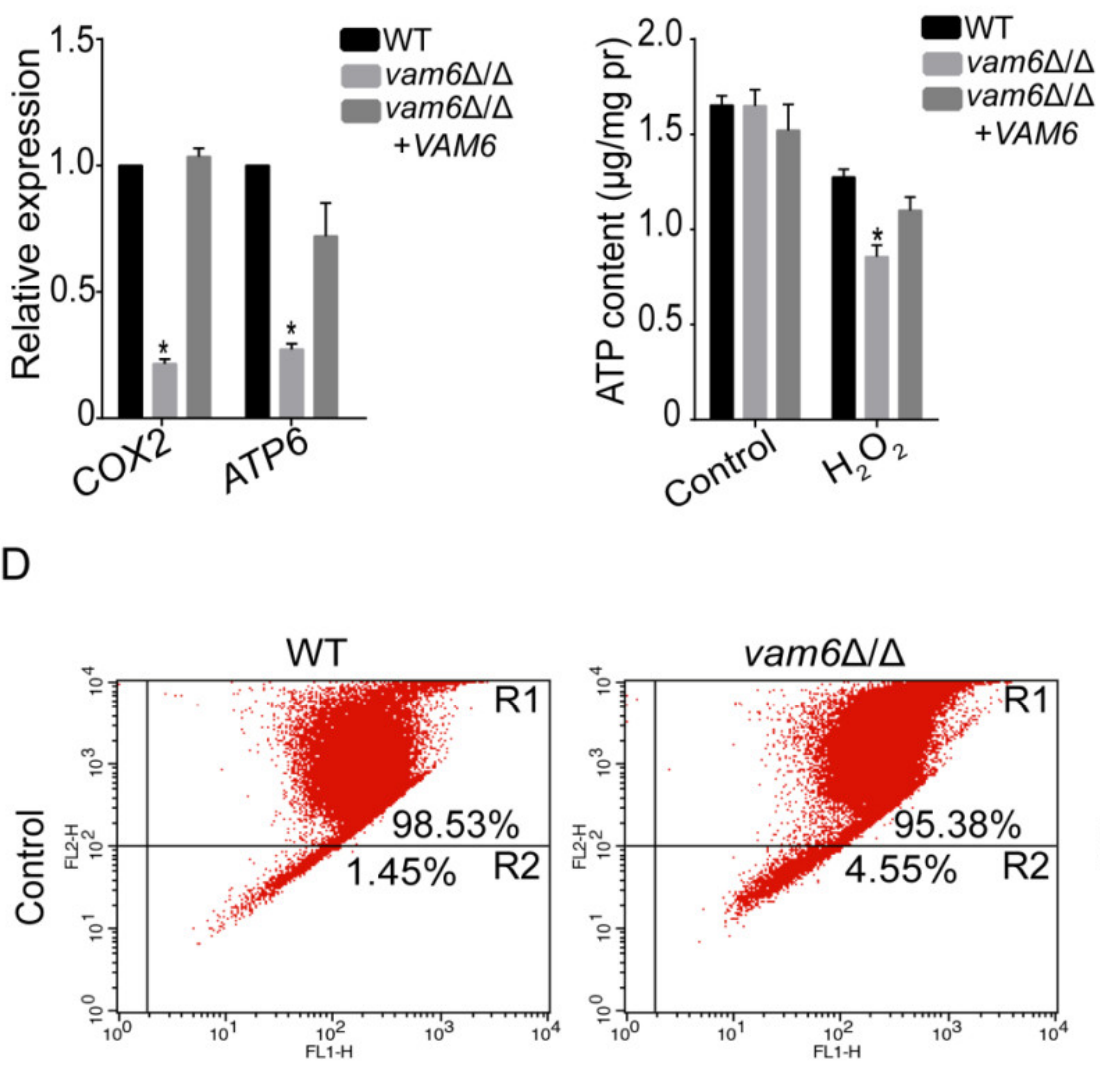

C

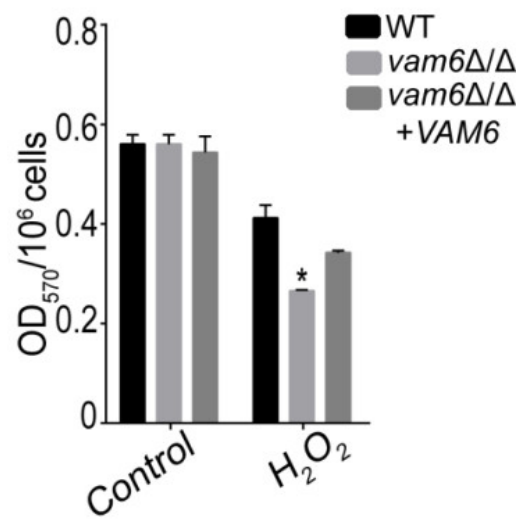

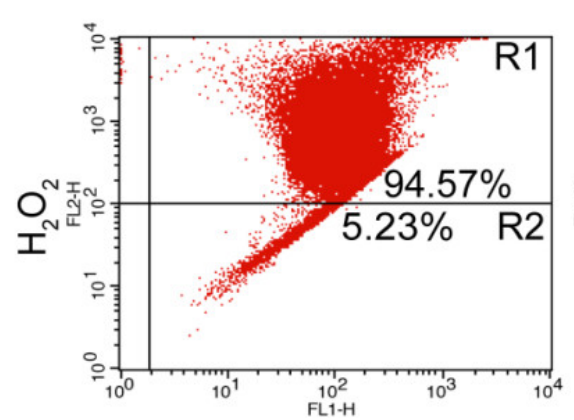
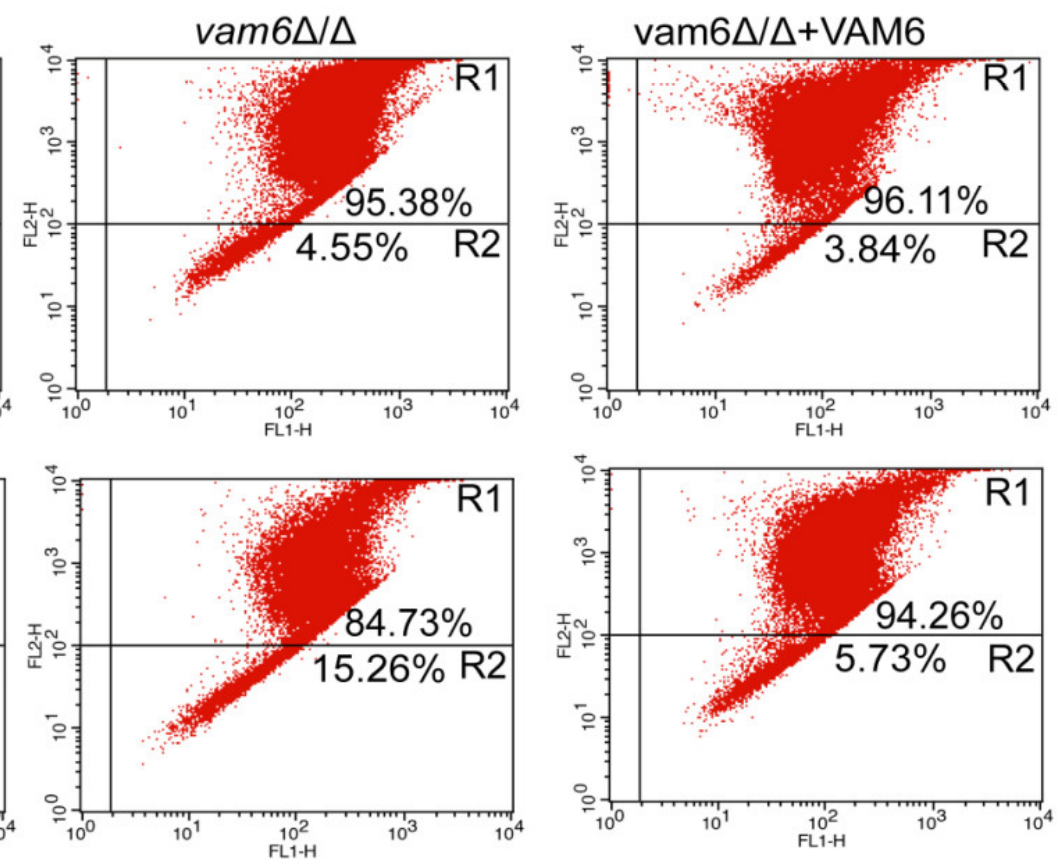

Figure 5. Deletion of VAM6 affects mitochondrial functions under oxidative stress. (A) Effect of VAM6 deletion on mtDNA quantity after cultured for $4 \mathrm{~h}$ under oxidative stress. The mtDNA encoding genes COX2, ATP6 were analyzed by RT-PCR using ACT1 as the normalization gene. (B) Intracellular ATP levelsmeasured by an ATP detection kit. (C) Impact of VAM6 deletion on mitochondrial SDH activity. Cultures were mixed with MTT and incubated at $30{ }^{\circ} \mathrm{C}$ for $2 \mathrm{~h}$, and then collected. The pellets were then resuspended in DMSO. The suspensions were centrifuged, and $\mathrm{OD}_{570}$ of the supernatants was measured. (D) Effect of VAM6 deletion on mitochondrial membrane potential revealed by JC-1 staining and flow cytometry. The cells were collected, resuspended in PBS and incubated with JC-1 for $30 \mathrm{~min}$ at $37^{\circ} \mathrm{C}$. Gated region R1 represents cells with intact mitochondrial membranes and gated region R2 shows cells with loss of mitochondrial membrane potential. This value represents the mean \pm SD from three replicates. * Significant difference between mutants and control strains, $p<0.05$.

\subsection{Effect of Vam6 on Oxidative Stress Response and Antioxidant Capacity}

Organisms use antioxidant enzymes (such as superoxide dismutases (SOD), catalase (CAT), etc.) to protect cells from oxidative damage by removing reactive oxygen species (ROS) [30]. In order to explore the mechanism of ROS accumulation in cells, the activity of SOD and CAT (encoding catalase) in the cells were measured. Enzymatic assays showed that oxidative stress caused remarkable increase in the activity of both SOD and CAT in the three strains (Figure 6A,B). As compared to the WT and reconstituted strains, the vam $6 \Delta / \Delta$ 
mutant exhibited obvious lower activity of both enzymes under oxidative stress, with 15 20\% lower SOD activity and 40 45\% lower CAT activity (Figure 6A,B). Moreover, the expression level of antioxidant genes (Thioredoxin reductase (TRR1), Glutathione reductase (GLR1), Copper-zinc superoxide dismutase 1 (SOD1), Catalase (CAT1)) was detected by qRT-PCR. Under $\mathrm{H}_{2} \mathrm{O}_{2}$ treatment for $2 \mathrm{~h}$, the expression levels of the SOD1 gene and the CAT1 gene were significantly reduced as compared to the control strains (Figure 6C). These results implied that VAM6 deletion had an impact on the antioxidant system under oxidative stress.

Some reports indicated that superoxide dismutases (SODs) play an essential role in protecting cells under oxidative conditions, and it is indispensable to elimination the superoxide anion radical $\left(\mathrm{O}_{2}{ }^{\bullet-}\right)$ in the cells [31]. The SOD1 $\left(\mathrm{Cu}^{2+} / \mathrm{Zn}^{2+}\right)$, SOD2 (Mn-SOD), SOD3 (Fe-SOD) were intracellular enzymes, while SOD4, SOD5, and SOD6 were GPIanchored superoxide dismutase that distribute on the cell wall surface [32]. Studies have shown that SOD1 and SOD2 can remove superoxide radical $\left(\mathrm{O}_{2}{ }^{\bullet-}\right)$ in eukaryotic cells [32]. In order to further study the mechanism of the SOD activity decrease in the mutant, the SOD1 (Copper/zinc superoxide dismutase) enzyme activity and ROS accumulation levels were examined. It can be seen that the addition of antioxidants, i.e., formic acid $\left(\mathrm{CH}_{2} \mathrm{O}_{2}\right)$ and NADH, could effectively recover SOD1 enzyme activity and reduce ROS accumulation level in vam6 $\Delta / \Delta$ under oxidative stress (Figure 6D,E). However, there was no significant change of SOD2 activity (results not shown). Our findings suggest that deletion of VAM6 reduces the antioxidant capacity of $\operatorname{vam} 6 \Delta / \Delta$ by reducing the SOD1 enzyme activity.

\subsection{Deletion of VAM6 Impairs Morphogenesis in C. albicans}

Studies have found that morphogenesis (e.g., hyphal development) is very important for the virulence of $C$. albicans [33]. There were many factors that affect the morphogenic ability of $C$. albicans. However, the effect of vCLAMPs on morphogenesis has not been reported in C. albicans. After culturing at $30^{\circ} \mathrm{C}$ and $37^{\circ} \mathrm{C}$, unlike the control strains forming wrinkled colonies with obvious hyphal extension, the vam $6 \Delta / \Delta$ mutant formed smooth colonies without wrinkles and hyphae around the colony (Figure 7A). Moreover, the WT, vam $6 \Delta / \Delta$, and reconstituted strains could all form hyphal cells in RPMI-1640 medium (Figure $7 \mathrm{~B}$ ). However, under the oxidative stress condition, while the WT and reconstituted strains could form hyphae after 10 12 h, the mutant failed to do so. These results confirmed that Vam6 plays an important role in hyphal development in C. albicans under oxidative stress conditions.

qRT-PCR experiments were performed to detect the expression of genes related to hyphae development in all strains. Under oxidative stress, the expression levels of hypharelating genes were reduced in vam $6 \Delta / \Delta$ strain (Figure $7 \mathrm{C}$ and Figure S4). These genes included the hyphal cell wall gene $H W P 1$, the biofilm formation-related gene ECE1, the cell membrane-related gene HYR1, and the adhesion-related gene ALS3 [34,35]. Above all, these results indicated that Vam6 is involved in hyphal development under oxidative stress, which is associated with regulation of expression of hypha-related genes. 
A

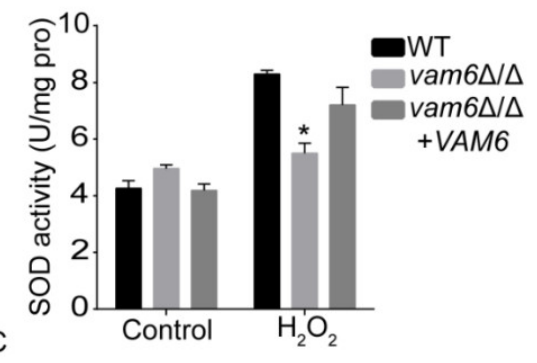

B
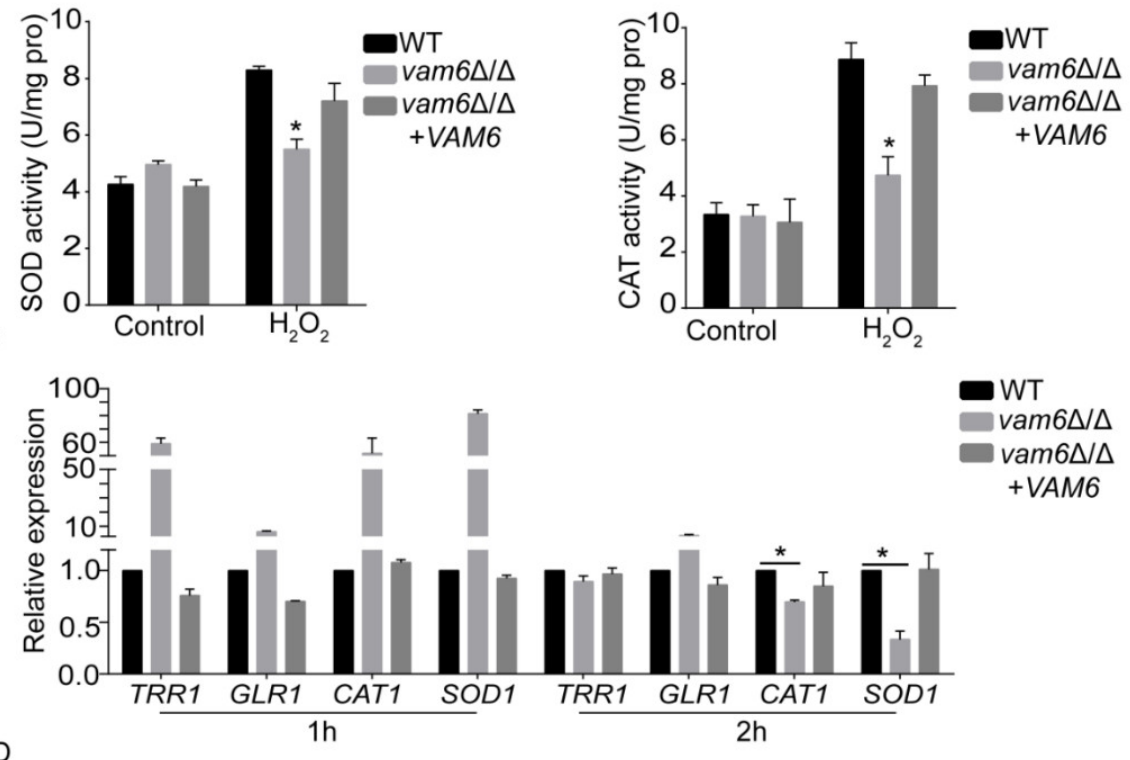

D

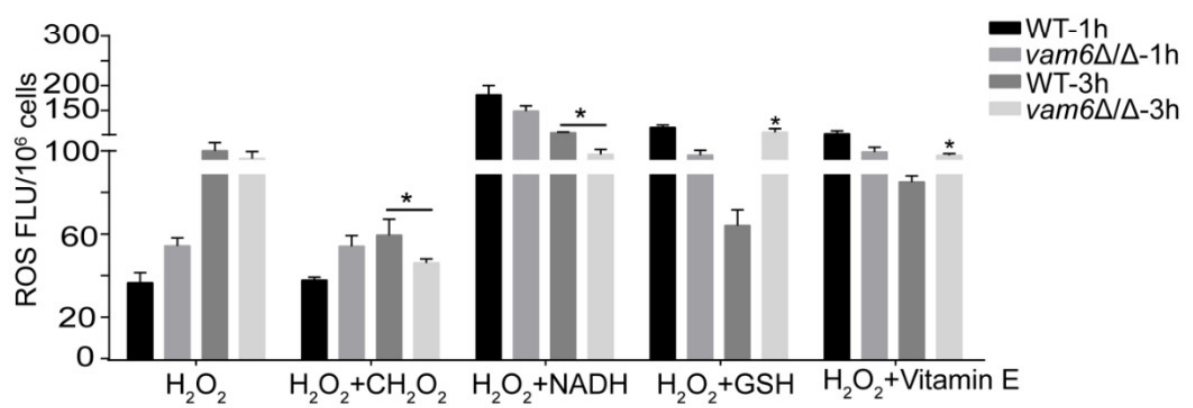

E

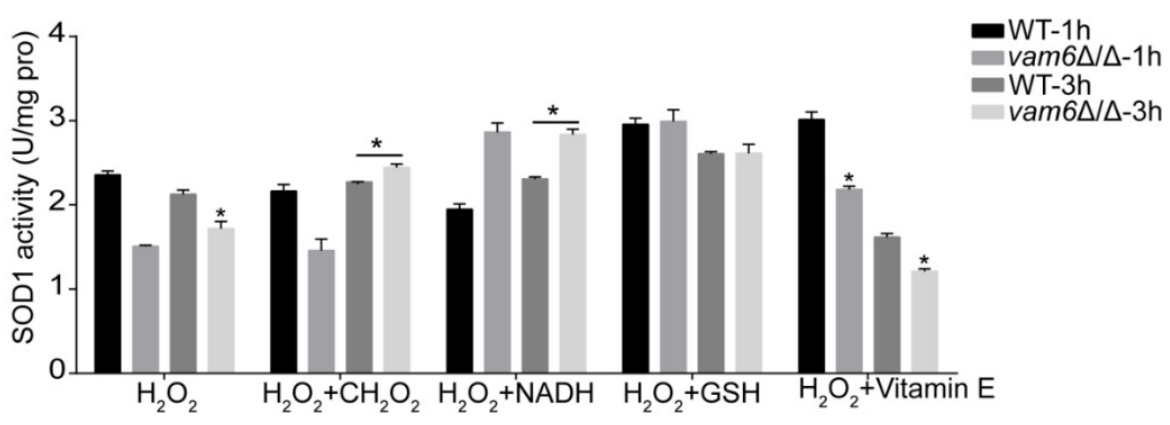

Figure 6. Deletion of VAM6 affected the antioxidant capacity of C. albicans. (A,B) Activity of SOD (A) and CAT (B) in the strains treated by $5 \mathrm{mM} \mathrm{H}_{2} \mathrm{O}_{2}$ or not. (C) Expression levels of oxidative stress-responsive genes in the strains revealed by RT-PCR, with ACT1 as the normalization gene. (D) Effect of antioxidants (i.e., $\mathrm{CH}_{2} \mathrm{O}_{2}, \mathrm{NADH}$, reduced glutathione (GSH), and Vitamin E) on intracellular ROS levels. Cells were cultured in YPD medium containing $5 \mathrm{mM} \mathrm{H}_{2} \mathrm{O}_{2}$ plus $50 \mathrm{mM} \mathrm{CH}_{2} \mathrm{O}_{2}, 50 \mu \mathrm{M} \mathrm{NADH}, 10 \mathrm{mM} \mathrm{GSH}, 10 \mathrm{mM}$ Vitamin E. After $1 \mathrm{~h}, 3 \mathrm{~h}$ of incubation with shaking at $30^{\circ} \mathrm{C}$. ROS were determined by DCFH-DA staining. (E) SOD1 activity in the $\mathrm{H}_{2} \mathrm{O}_{2}$-treated cells. SOD1 activity of the supernatant was assessed by a SOD1 assay kit. The values represent the mean \pm SD from three replicates. * indicates a significant difference between mutants and the control strains $(p<0.05)$. 
A

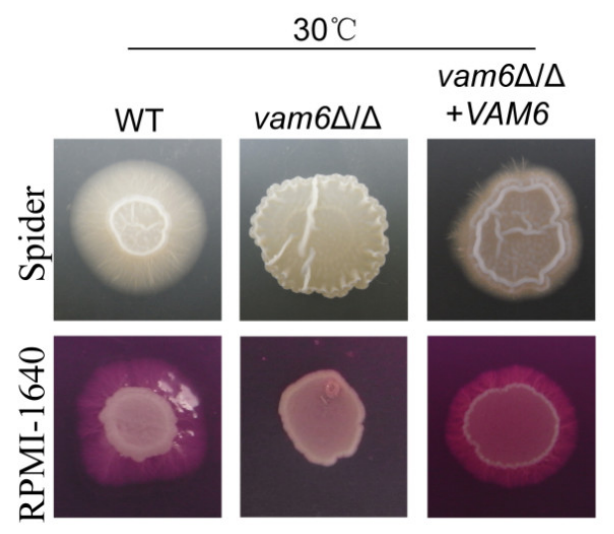

B
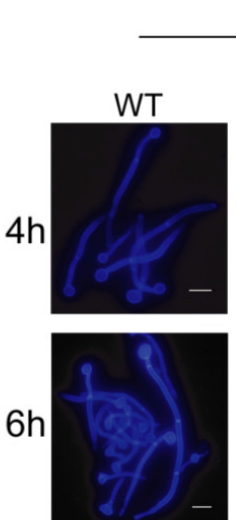

Control

$\operatorname{vam} 6 \Delta / \Delta$

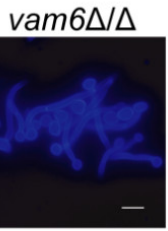

+VAM6
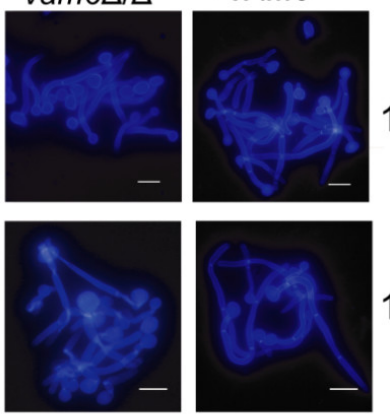

C

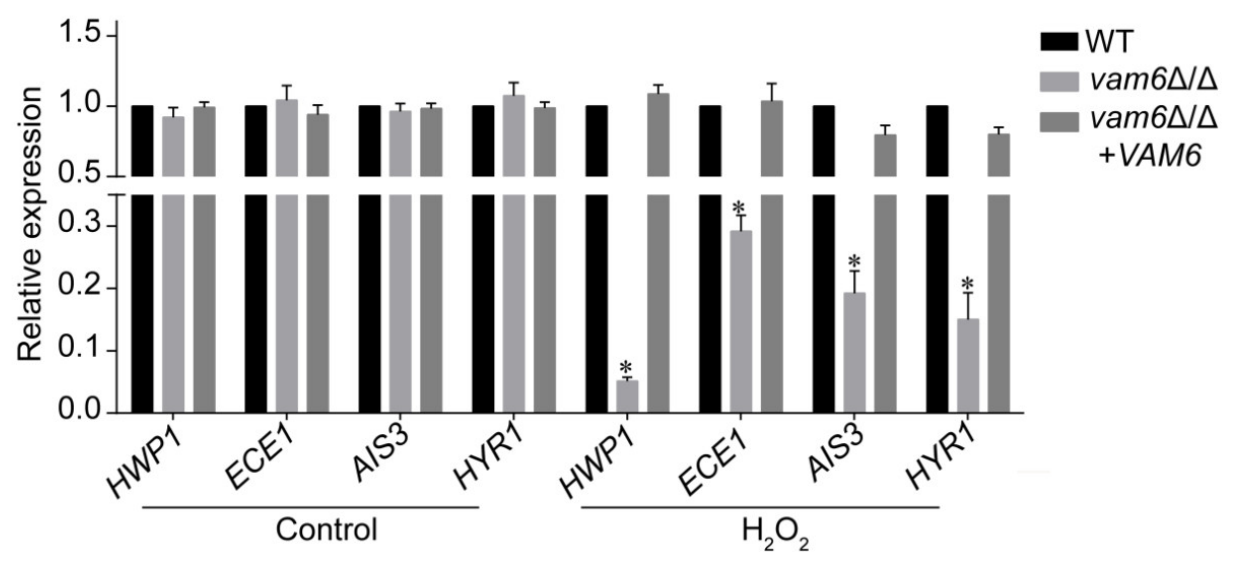

Figure 7. The effect of VAM6 deletion on hyphal development of C. albicans. (A) Hyphal development on the solid hypha-inducing media. The strains were spotted on the indicated agar plates and incubated at $30^{\circ} \mathrm{C}$ or $37^{\circ} \mathrm{C}$ for five days. (B) Hyphal development in the liquid RPMI-1640 medium in the absence of (Control) or in the presence of $\mathrm{H}_{2} \mathrm{O}_{2}$. Left, the cells were incubated in the medium at $37^{\circ} \mathrm{C}$ for $2 \mathrm{~h}, 4 \mathrm{~h}$, or $6 \mathrm{~h}$, and stained by CFW for observation. Right, the strains were incubated in liquid RPMI- 1640 containing $5 \mathrm{mM} \mathrm{H}_{2} \mathrm{O}_{2}$ at $37^{\circ} \mathrm{C}$ for $10 \mathrm{~h}$ or $12 \mathrm{~h}$, and stained by CFW then observed. Bar $=5 \mu \mathrm{m}$. (C) Effect of VAM6 deletion on expression of hypha related genes. Cells were collected after treated by $5 \mathrm{mM} \mathrm{H}_{2} \mathrm{O}_{2}$ in liquid RPMI- 1640 medium for $1 \mathrm{~h}$, and then RNA was extracted. The expression of AIS3, ECE1, HYR1, and HWP1 were measured by RT-PCR using $A C T 1$ as the normalization gene. The relative measurement was respectively under control and $\mathrm{H}_{2} \mathrm{O}_{2}$ conditions. This value represents the mean $\pm \mathrm{SD}$ with three replicates. * indicates a significant difference between the mutant and the control strains $(p<0.05)$. 


\subsection{Deletion of VAM6 Dramatically Reduces the Virulence of C. albicans}

The above results revealed that Vam6 is involved in maintaining both vacuolar and mitochondrial functions, together with regulation of morphogenesis, all of which are associated with the virulence of $C$. albicans. Therefore, we speculated that VAM6 deletion may reduce the pathogenicity of $C$. albicans. We used both the $C$. albicans-macrophage interaction model and the mouse systemic infection model to investigate the function of Vam6 in the pathogenesis of C. albicans. Since URA3 can influence the virulence of C. albicans, we reintroduced URA3 to the strains by the plasmid pLUBP to ensure the accuracy of virulence experiment results [36]. These mutants were named $\mathrm{WT}^{\mathrm{a}}$, vam6 $6 / \Delta^{\mathrm{a}}$, vam6 $\Delta / \triangle+V A M 6^{\mathrm{a}}$.

The macrophage-killing ability of $C$. albicans was determined by the $C$. albicansmacrophage interaction model. We found that the killing capacity of vam $6 \Delta / \Delta$ was reduced, compared the control strains (Figure 8A). While the control strains could kill $60 \%$ macrophages, the mutant only killed $\sim 30 \%$ macrophages (Figure $8 \mathrm{~A}$ ). Therefore, deletion of VAM6 severely attenuated the capacity of the fungal cells to kill macrophages.

A

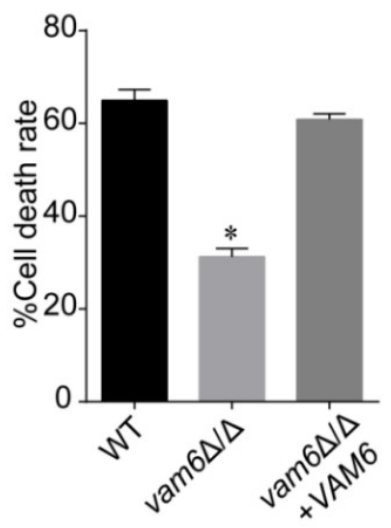

C

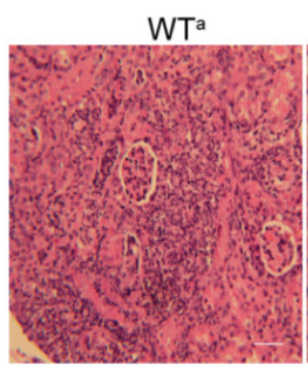

B

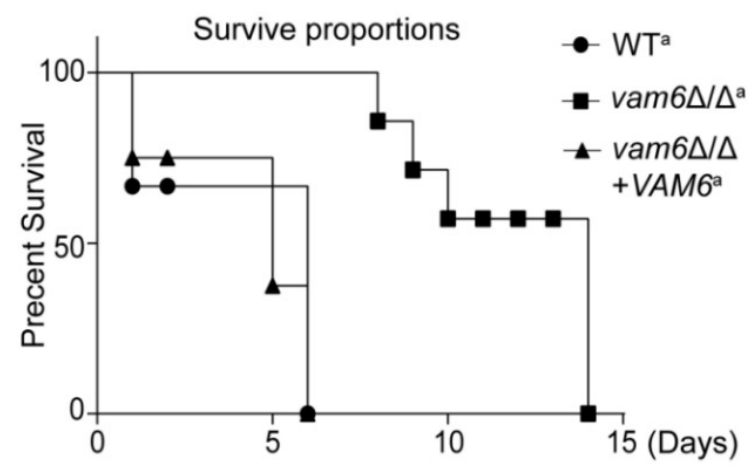

D
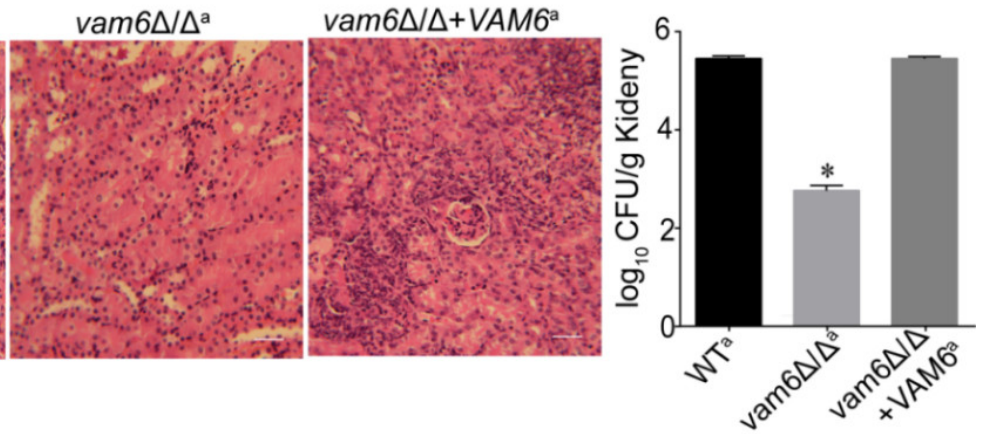

Figure 8. Effect of VAM6 deletion on virulence of C. albicans. (A) Macrophage-killing capacity of the strains $\mathrm{WT}^{\mathrm{a}}$, vam $6 \Delta / \Delta^{\mathrm{a}}$, vam $6 \Delta / \triangle+V A M 6^{\mathrm{a}}$. (B) Survival rate of the mice infected by the strains. (C) Histopathological images of the kidneys infected by the strains. Bar $=50 \mu \mathrm{m}$. (D) Fungal burden in the kidney suffering from infection by the strains after five days. * indicates significant difference between the control strains and the mutant $(p<0.05)$. Values represent mean \pm SD.

To further test the effect of VAM6 deletion on the virulence of $C$. albicans, a systematic mouse infection model was further used. While all mice infected by the WT and reconstituted strains died in five days, all the mice infected with vam $6 \Delta / \Delta^{\mathrm{a}}$ survived in these days, and died after 15 days, revealing that deletion of VAM6 prolonged the survival time of the fungus-infected mice. Moreover, it was found that the mouse kidneys infected by the mutant had lower inflammation degree (Figure 8C and Figure S5), and exhibited much lower fungal burden than the kidneys infected by the control strains (Figure 8D). 
Together, these results confirm that Vam6 plays an important role in the pathogenicity of C. albicans cells.

\section{Discussion}

Previous studies revealed that $\mathrm{ScVps39}$ is a vCLAMP protein in S. cerevisiae [17]. However, the cellular biological functions of C. albicans Vam6, the homolog of ScVps39, have been less widely studied. In this study, we confirmed that Vam6 is a core vCLAMP protein in C. albicans. Based on fluorescence microscopy techniques and immunotransmission electron microscope (IEM), we found that the Vam6 protein localized on the connection site of mitochondria and vacuoles in C. albicans (Figure 1). Furthermore, deletion of VAM6 significantly reduced the number of vCLAMPs. Above all, we successfully confirmed the role of Vam6 in vCLAMP formation of C. albicans. Our work provides a new insight in vCLAMPs of this pathogen.

In this study, deletion of VAM6 caused a defect in vacuolar fusion in C. albicans (Figure 3A). In recent years, some research has found that deletion of ScVps39 causes vacuoles to form numerous small vesicles in S. cerevisiae, which is consistent with the findings of our study $[15,17]$. It was found that loss of $\mathrm{CmVps} 39$ also made the vacuoles smaller in Coniothyrium minitans. Vacuoles can be formed by aggregation of small vesicles to form large vacuoles, or by split of large vacuoles in C. albicans $[15,17,37]$. Fusion and division of vacuoles were indispensable to maintain normal cell viability [38]. ScVps39, as a vacuolar Rab/Ypt effector, cooperates with Ypt7p to mediate and promote vacuolar fusion in S. cerevisiae [39]. Those results indicated that $\mathrm{ScVps} 39$ is an important factor for vacuolar fusion. It has been reported that vacuole have the function of adjusting $\mathrm{pH}$ balance in S. cerevisiae [40]. Herein, we found that the vam $6 \Delta / \Delta$ mutant failed to maintain acidic $\mathrm{pH}$ under oxidative stress. Some reports point that acidic environment of vacuoles was very important to maintain the enzyme activity in C. albicans [25]. We speculate that the abnormal vacuolar $\mathrm{pH}$ is due to the morphology change of the vacuoles, which results in the decrease of the acid-base balance enzyme activity under oxidative stress. The study revealed that the VCLAMP protein Vam6 was necessary to maintain vacuolar acidity under oxidative stress. In addition, our data leave open the question of the VAM6 deletion significantly increasing the sensitivity to copper ions in C. albicans, which was different to the findings in S. cerevisiae [17]. The mechanism needs further study. In summary, these results suggested that Vam6 plays a vital role in maintaining vacuole morphology and functions of $C$. albicans.

The mitochondrion is the antioxidant center of eukaryotic cells. It was not only the main ROS-generating site, but also the ROS removing site [41]. In recent years, some researches indicated that the mitochondria were attacked by ROS when the cell's antioxidant capacity was compromised. ROS caused oxidative damage to the mitochondria by reduction of cardiolipin synthesis, degradation of mtDNA and inactivation of mitochondrial proteins [41]. The results of this study indicate that deletion of VAM6 caused abnormal mitochondrial morphology (Figure 4). Moreover, the expression levels of mtDNA [13,42], e.g., COX2, ATP6 were significantly reduced under oxidative stress (Figure 5A). Mitochondrial membrane potential and SDH activity were also dramatically reduced in vam $6 \Delta / \Delta$ mutant $[43,44]$. Those results indicated that the vCLAMP core protein Vam6 is important to maintenance of mitochondrial functions under oxidative stress.

Some studies have shown that accumulation of dysfunctional mitochondria may cause accumulation of ROS in cells [41,45]. Interestingly, deletion of the VAM6 gene caused a significant increase of ROS in vam $6 \Delta / \Delta$. We speculated that high levels of ROS may be due to the reduced ROS-scavenging enzyme activity. In this study, the expression of ROS scavenging enzymes (SOD and CAT) and related genes were significantly decreased under oxidative stress in vam $6 \Delta / \Delta$ [46]. Some reports pointed out that once C. albicans successfully infects host tissues, the fungal oxidative stress response system is activated, and the secretion of anti-oxidant enzymes becomes important to resist oxidative stress. Among them, superoxide dismutases (SODs) play a critical role in ROS removal. 
Studies have shown that SOD1 and SOD2 exist in eukaryotic cells [32], and remove superoxide anions of intracellular. Therefore, we speculate that the significant accumulation of ROS was due to decreased SOD enzyme activity in the mutant. It was found that only the addition of superoxide scavengers, such as $\mathrm{CH}_{2} \mathrm{O}_{2}$ and $\mathrm{NADH}$, can reduce the accumulation of ROS under oxidative stress [47]. However, there was no significant change of SOD2 activity. Therefore, the present research work brought about a discovery that the abnormal antioxidant capacity was due to a decrease of SOD1 enzyme activity in vam6 $6 / \Delta$. These findings confirmed that the vCLAMP core protein Vam6 was of significance to oxidative stress resistance.

Herein, Vam6 was also involved in hyphal development. Under oxidative stress, deletion of VAM6 led to significant abnormalities in hyphal development of $C$. albicans. The above findings can be summarized as follows. (1) As a key organelle of the fungus, the vacuoles participate in long-distance transportation of nutrients within the hypha, and can also regulate the expansion and branch formation of the fungal hypha [48,49]. This research found that deletion of VAM6 caused abnormal vacuolar morphology, and led to a defect in vacuolar fusion. Therefore, we speculate that the process of intracellular nutrient transport involved in cells was blocked, which makes it difficult to transport nutrients to the growth point for hyphal development. (2) The mitochondria are the core of energy production, and the main place for aerobic respiration in cells. Some reports found that mycelium development requires mitochondria to provide energy. For example, studies have shown that mitochondrial ATP synthases were involved in regulating ascospore germination and sexual reproduction in Podospora anserina [50]. The results reported here support that mitochondrial morphology was abnormal and the ridge was loose in vam $6 \Delta / \Delta$ under oxidative stress. The results presented here suggested that the mitochondrial functions were impaired, leading to decreased energy metabolism required for hyphal development. (3) Cell viability affects hyphal development of C. alibcans. In this study loss of Vam6 rendered the cell viability under oxidative stress. Therefore, we speculate that the action of $\mathrm{H}_{2} \mathrm{O}_{2}$ did not lead to hyphal development in vam $6 \Delta / \Delta$ mutant. The synergistic effect of various virulence factors of $C$. albicans leads to an increase or decrease of its pathogenicity. When an imbalance of certain factors occurs, the ability of the pathogen to infect the host will be weakened. As a core protein of vCLAMPs, Vam6 plays an important role in maintaining oxidative stress resistance, hyphal development, and virulence of C. albicans.

\section{Conclusions}

This study revealed that the vCLAMP protein Vam6 is critical for the formation of the vCLAMP structure, oxidative stress tolerance, and maintenance of mitochondrial and vacuolar functions under oxidative stress. The wide-ranging functions of Vam6 make it an important factor required for the maintenance of the virulence of this pathogen. Therefore, vCLAMPs may be a novel target of antifungal therapies for the treatment of C. albicans-related infections.

Supplementary Materials: The following are available online at https://www.mdpi.com/2076 -3921/10/1/136/s1, Figure S1: Construction and identification of vam6 $\Delta / \Delta$ mutants, Figure S2: Localization of Csp37 was observer in WT-CSP37-GFP, Figure S3: Ions sensitivity analysis of the vam $6 \Delta / \triangle$ mutant, Figure S4: Effect of VAM6 deletion on expression of hypha related genes, Figure S5: Quantify the tissue damage of kidneys, Table S1: Strains and plasmids used in this study, Table S2: Primers used in this study. References $[1,51,52]$ are cited in the Supplementary Material.

Author Contributions: Conceived and designed the experiments and wrote the paper, X.M., M.L.; performed the experiments, L.Y.; C.M. and T.M. and Q.Y.; analyzed the data, Y.L.; supervision, M.L. All authors have read and agreed to the published version of the manuscript.

Funding: This research was funded by the National Natural Science Foundation of China (81873961, 32070145, 31870139), and the Natural Science Foundation of Tianjin (17JCZDJC33300).

Institutional Review Board Statement: The study was approved by the Ethics Committee of Nankai University (permit number NK20160004). 
Informed Consent Statement: Not applicable.

Data Availability Statement: Data is contained within the article or Supplementary Material.

Acknowledgments: We thank Dana Davis (University of Minnesota, USA) and Steven Bates (University of Exeter, UK) for generously providing strains and plasmids.

Conflicts of Interest: The authors declare that the research was conducted in the absence of any commercial or financial relationships that could be construed as a potential conflict of interest.

\section{References}

1. Yu, Q.; Zhang, B.; Yang, B.; Chen, J.; Wang, H.; Jia, C.; Ding, X.; Xu, N.; Dong, Y.; Zhang, B.; et al. Interaction among the vacuole, the mitochondria, and the oxidative stress response is governed by the transient receptor potential channel in Candida albicans. Free Radic. Biol. Med. 2014, 77, 152-167. [CrossRef] [PubMed]

2. Sheevani, P.S.; Aggarwal, A. Nosocomial Candida infection in a rural tertiary care hospital. J. Clin. Diagn. Res. 2013, 7, 405-406. [CrossRef] [PubMed]

3. Gunsalus, K.T.; Tornberg-Belanger, S.N.; Matthan, N.R.; Lichtenstein, A.H.; Kumamoto, C.A. Manipulation of Host Diet To Reduce Gastrointestinal Colonization by the Opportunistic Pathogen Candida albicans. mSphere 2016, 1. [CrossRef] [PubMed]

4. Dong, Y.; Yu, Q.; Chen, Y.; Xu, N.; Zhao, Q.; Jia, C.; Zhang, B.; Zhang, K.; Zhang, B.; Xing, L.; et al. The Ccz1 mediates the autophagic clearance of damaged mitochondria in response to oxidative stress in Candida albicans. Int. J. Biochem. Cell Biol. 2015, 69, 41-51. [CrossRef] [PubMed]

5. Almeida, R.S.; Wilson, D.; Hube, B. Candida albicans iron acquisition within the host. FEMS Yeast Res. 2009, 9, 1000-1012. [CrossRef] [PubMed]

6. Enjalbert, B.; MacCallum, D.M.; Odds, F.C.; Brown, A.J. Niche-specific activation of the oxidative stress response by the pathogenic fungus Candida albicans. Infect. Immun. 2007, 75, 2143-2151. [CrossRef]

7. Palmer, G.E. Vacuolar trafficking and Candida albicans pathogenesis. Commun. Integr. Biol. 2011, 4, 240-242. [CrossRef]

8. Molero, G.; Diez-Orejas, R.; Navarro-Garcia, F.; Monteoliva, L.; Pla, J.; Gil, C.; Sanchez-Perez, M.; Nombela, C. Candida albicans: Genetics, dimorphism and pathogenicity. Int. Microbiol. 1998, 1, 95-106.

9. Saville, S.P.; Lazzell, A.L.; Monteagudo, C.; Lopez-Ribot, J.L. Engineered control of cell morphology in vivo reveals distinct roles for yeast and filamentous forms of Candida albicans during infection. Eukaryot. Cell 2003, 2, 1053-1060. [CrossRef]

10. Bauerova, V.; Hajek, M.; Pichova, I.; Hruskova-Heidingsfeldova, O. Intracellular aspartic proteinase Apr1p of Candida albicans is required for morphological transition under nitrogen-limited conditions but not for macrophage killing. Folia Microbiol. 2014, 59, 485-493. [CrossRef]

11. Vacca, R.A.; de Pinto, M.C.; Valenti, D.; Passarella, S.; Marra, E.; De Gara, L. Production of reactive oxygen species, alteration of cytosolic ascorbate peroxidase, and impairment of mitochondrial metabolism are early events in heat shock-induced programmed cell death in tobacco Bright-Yellow 2 cells. Plant Physiol. 2004, 134, 1100-1112. [CrossRef] [PubMed]

12. Herlan, M.; Vogel, F.; Bornhovd, C.; Neupert, W.; Reichert, A.S. Processing of Mgm1 by the rhomboid-type protease Pcp1 is required for maintenance of mitochondrial morphology and of mitochondrial DNA. J. Biol. Chem. 2003, 278, 27781-27788. [CrossRef] [PubMed]

13. Liang, C.; Zhang, B.; Cui, L.; Li, J.; Yu, Q.; Li, M. Mgm1 is required for maintenance of mitochondrial function and virulence in Candida albicans. Fungal Genet. Biol. 2018, 120, 42-52. [CrossRef] [PubMed]

14. Ungermann, C. vCLAMPs-an intimate link between vacuoles and mitochondria. Curr. Opin. Cell Biol. 2015, 35, 30-36. [CrossRef] [PubMed]

15. González Montoro, A.; Auffarth, K.; Hönscher, C.; Bohnert, M.; Becker, T.; Warscheid, B.; Reggiori, F.; van der Laan, M.; Fröhlich, F.; Ungermann, C. Vps39 Interacts with Tom40 to Establish One of Two Functionally Distinct Vacuole-Mitochondria Contact Sites. Dev. Cell 2018, 45, 621-636.e627. [CrossRef]

16. John Peter, A.T.; Herrmann, B.; Antunes, D.; Rapaport, D.; Dimmer, K.S.; Kornmann, B. Vps13-Mcp1 interact at vacuolemitochondria interfaces and bypass ER-mitochondria contact sites. J. Cell Biol. 2017, 216, 3219-3229. [CrossRef]

17. Nakamura, N.; Hirata, A.; Ohsumi, Y.; Wada, Y. Vam2/Vps41p and Vam6/Vps39p are components of a protein complex on the vacuolar membranes and involved in the vacuolar assembly in the yeast Saccharomyces cerevisiae. J. Biol. Chem. 1997, 272, 11344-11349. [CrossRef]

18. Wilson, R.B.; Davis, D.; Enloe, B.M.; Mitchell, A.P. A recyclable Candida albicans URA3 cassette for PCR product-directed gene disruptions. Yeast 2000, 16, 65-70. [CrossRef]

19. Poot, M.; Gibson, L.L.; Singer, V.L. Detection of apoptosis in live cells by MitoTracker red CMXRos and SYTO dye flow cytometry. Cytometry 1997, 27, 358-364. [CrossRef]

20. Fischer-Parton, S.; Parton, R.M.; Hickey, P.C.; Dijksterhuis, J.; Atkinson, H.A.; Read, N.D. Confocal microscopy of FM4-64 as a tool for analysing endocytosis and vesicle trafficking in living fungal hyphae. J. Microsc. 2000, 198, 246-259. [CrossRef]

21. Li, H.X.; Xiao, Y.; Cao, L.L.; Yan, X.; Li, C.; Shi, H.Y.; Wang, J.W.; Ye, Y.H. Cerebroside C increases tolerance to chilling injury and alters lipid composition in wheat roots. PLoS ONE 2013, 8, e73380. [CrossRef] [PubMed] 
22. Kanki, T.; Kang, D.; Klionsky, D.J. Monitoring mitophagy in yeast: The Om45-GFP processing assay. Autophagy 2009, 5, 1186-1189. [CrossRef] [PubMed]

23. Peralta, E.R.; Martin, B.C.; Edinger, A.L. Differential effects of TBC1D15 and mammalian Vps39 on Rab7 activation state, lysosomal morphology, and growth factor dependence. J. Biol. Chem. 2010, 285, 16814-16821. [CrossRef] [PubMed]

24. Olsen, I. Attenuation of Candida albicans virulence with focus on disruption of its vacuole functions. J. Oral Microbiol. 2014, 6. [CrossRef] [PubMed]

25. Jia, C.; Zhang, K.; Zhang, D.; Yu, Q.; Zhao, Q.; Xiao, C.; Dong, Y.; Chu, M.; Li, M. Roles of VPH2 and VMA6 in localization of V-ATPase subunits, cell wall functions and filamentous development in Candida albicans. Fungal Genet. Biol. 2018, $114,1-11$. [CrossRef] [PubMed]

26. AhYoung, A.P.; Jiang, J.; Zhang, J.; Khoi Dang, X.; Loo, J.A.; Zhou, Z.H.; Egea, P.F. Conserved SMP domains of the ERMES complex bind phospholipids and mediate tether assembly. Proc. Natl. Acad. Sci. USA 2015, 112, E3179-E3188. [CrossRef] [PubMed]

27. Wang, X.; Zhang, X.; Wu, D.; Huang, Z.; Hou, T.; Jian, C.; Yu, P.; Lu, F.; Zhang, R.; Sun, T.; et al. Mitochondrial flashes regulate ATP homeostasis in the heart. eLife 2017, 6. [CrossRef]

28. Bulthuis, E.P.; Adjobo-Hermans, M.J.W.; Willems, P.; Koopman, W.J.H. Mitochondrial Morphofunction in Mammalian Cells. Antioxid. Redox Signal. 2019, 30, 2066-2109. [CrossRef]

29. Ly, J.D.; Grubb, D.R.; Lawen, A. The mitochondrial membrane potential (deltapsi(m)) in apoptosis; an update. Apoptosis Int. J. Program. Cell Death 2003, 8, 115-128. [CrossRef]

30. Chekulayeva, L.V.; Shevchuk, I.N.; Chekulayev, V.A.; Ilmarinen, K. Hydrogen peroxide, superoxide, and hydroxyl radicals are involved in the phototoxic action of hematoporphyrin derivative against tumor cells. J. Environ. Pathol. Toxicol. Oncol. 2006, 25, 51-77. [CrossRef]

31. Kloppel, C.; Michels, C.; Zimmer, J.; Herrmann, J.M.; Riemer, J. In yeast redistribution of Sod1 to the mitochondrial intermembrane space provides protection against respiration derived oxidative stress. Biochem. Biophys. Res. Commun. 2010, 403, 114-119. [CrossRef] [PubMed]

32. Frohner, I.E.; Bourgeois, C.; Yatsyk, K.; Majer, O.; Kuchler, K. Candida albicans cell surface superoxide dismutases degrade host-derived reactive oxygen species to escape innate immune surveillance. Mol. Microbiol. 2009, 71, 240-252. [CrossRef] [PubMed]

33. Zhang, B.; Yu, Q.; Jia, C.; Wang, Y.; Xiao, C.; Dong, Y.; Xu, N.; Wang, L.; Li, M. The actin-related protein Sac1 is required for morphogenesis and cell wall integrity in Candida albicans. Fungal Genet. Biol. 2015, 81, 261-270. [CrossRef] [PubMed]

34. Fan, Y.; He, H.; Dong, Y.; Pan, H. Hyphae-specific genes HGC1, ALS3, HWP1, and ECE1 and relevant signaling pathways in Candida albicans. Mycopathologia 2013, 176, 329-335. [CrossRef] [PubMed]

35. Samaranayake, Y.H.; Cheung, B.P.; Yau, J.Y.; Yeung, S.K.; Samaranayake, L.P. Human serum promotes Candida albicans biofilm growth and virulence gene expression on silicone biomaterial. PLoS ONE 2013, 8, e62902. [CrossRef]

36. Brand, A.; MacCallum, D.M.; Brown, A.J.; Gow, N.A.; Odds, F.C. Ectopic expression of URA3 can influence the virulence phenotypes and proteome of Candida albicans but can be overcome by targeted reintegration of URA3 at the RPS10 locus. Eukaryot. Cell 2004, 3, 900-909. [CrossRef]

37. Price, A.; Seals, D.; Wickner, W.; Ungermann, C. The docking stage of yeast vacuole fusion requires the transfer of proteins from a cis-SNARE complex to a Rab/Ypt protein. J. Cell Biol. 2000, 148, 1231-1238. [CrossRef]

38. Oka, M.; Maruyama, J.; Arioka, M.; Nakajima, H.; Kitamoto, K. Molecular cloning and functional characterization of avaB, a gene encoding Vam6p/Vps39p-like protein in Aspergillus nidulans. FEMS Microbiol. Lett. 2004, 232, 113-121. [CrossRef]

39. Jahn, R.; Scheller, R.H. SNAREs-Engines for membrane fusion. Nat. Rev. Mol. Cell Biol. 2006, 7, 631-643. [CrossRef]

40. Kane, P.M. The long physiological reach of the yeast vacuolar H+-ATPase. J. Bioenergy Biomembr. 2007, 39, 415-421. [CrossRef]

41. Diebold, L.; Chandel, N.S. Mitochondrial ROS regulation of proliferating cells. Free Radic. Biol. Med. 2016, 100, 86-93. [CrossRef] [PubMed]

42. Neubauer, M.; Zhu, Z.; Penka, M.; Helmschrott, C.; Wagener, N.; Wagener, J. Mitochondrial dynamics in the pathogenic mold Aspergillus fumigatus: Therapeutic and evolutionary implications. Mol. Microbiol. 2015, 98, 930-945. [CrossRef] [PubMed]

43. Huang, T.J.; Price, S.A.; Chilton, L.; Calcutt, N.A.; Tomlinson, D.R.; Verkhratsky, A.; Fernyhough, P. Insulin prevents depolarization of the mitochondrial inner membrane in sensory neurons of type 1 diabetic rats in the presence of sustained hyperglycemia. Diabetes 2003, 52, 2129-2136. [CrossRef] [PubMed]

44. Qu, S.; Dai, C.; Guo, H.; Wang, C.; Hao, Z.; Tang, Q.; Wang, H.; Zhang, Y. Rutin attenuates vancomycin-induced renal tubular cell apoptosis via suppression of apoptosis, mitochondrial dysfunction, and oxidative stress. Phytother. Res. 2019, 33, $2056-2063$. [CrossRef] [PubMed]

45. Hwang, J.H.; Hwang, I.S.; Liu, Q.H.; Woo, E.R.; Lee, D.G. (+)-Medioresinol leads to intracellular ROS accumulation and mitochondria-mediated apoptotic cell death in Candida albicans. Biochimie 2012, 94, 1784-1793. [CrossRef] [PubMed]

46. Brookes, P.S.; Yoon, Y.; Robotham, J.L.; Anders, M.W.; Sheu, S.S. Calcium, ATP, and ROS: A mitochondrial love-hate triangle. Am. J. Physiol. Cell Physiol. 2004, 287, C817-C833. [CrossRef] [PubMed]

47. Albers, D.S.; Beal, M.F. Mitochondrial dysfunction and oxidative stress in aging and neurodegenerative disease. J. Neural Transm. Suppl. 2000, 59, 133-154. [PubMed] 
48. Barelle, C.J.; Priest, C.L.; Maccallum, D.M.; Gow, N.A.; Odds, F.C.; Brown, A.J. Niche-specific regulation of central metabolic pathways in a fungal pathogen. Cell. Microbiol. 2006, 8, 961-971. [CrossRef]

49. Lima, E.C.; Royer, B.; Vaghetti, J.C.; Simon, N.M.; da Cunha, B.M.; Pavan, F.A.; Benvenutti, E.V.; Cataluna-Veses, R.; Airoldi, C. Application of Brazilian pine-fruit shell as a biosorbent to removal of reactive red 194 textile dye from aqueous solution kinetics and equilibrium study. J. Hazard. Mater. 2008, 155, 536-550. [CrossRef]

50. Dequard-Chablat, M.; Sellem, C.H.; Golik, P.; Bidard, F.; Martos, A.; Bietenhader, M.; di Rago, J.P.; Sainsard-Chanet, A.; HermannLe Denmat, S.; Contamine, V. Two nuclear life cycle-regulated genes encode interchangeable subunits c of mitochondrial ATP synthase in Podospora anserina. Mol. Biol. Evol. 2011, 28, 2063-2075. [CrossRef]

51. Wilson, R.B.; Davis, D.; Mitchell, A.P. Rapid hypothesis testing with Candida albicans through gene disruption with short homology regions. Journal of bacteriology 1999, 181, 1868-1874. [CrossRef] [PubMed]

52. Ramón, A.M.; Fonzi, W.A. Diverged binding specificity of Rim101p, the Candida albicans ortholog of PacC. Eukaryotic Cell 2003, 2, 718-728. [CrossRef] 